\title{
Identifying the Sources of Continental Summertime Temperature Variance Using a Diagnostic Model of Land-Atmosphere Interactions
}

\author{
L. R. VARgas Zeppetello, Étienne Tétreault-PinARd, ${ }^{a}$ D. S. BAtTisti, AND M. B. BAKeR ${ }^{\mathrm{b}}$ \\ Department of Atmospheric Sciences, University of Washington, Seattle, Washington
}

(Manuscript received 12 April 2019, in final form 22 January 2020)

\begin{abstract}
Climate models show that soil moisture and its subseasonal fluctuations have important impacts on the surface latent heat flux, thus regulating surface temperature variations. Using correlations between monthly anomalies in net absorbed radiative fluxes, precipitation, 2-m air temperature, and soil moisture in the ERAInterim reanalysis and the HadCM3 climate model, we develop a linear diagnostic model to quantify the major effects of land-atmosphere interactions on summertime surface temperature variability. The spatial patterns in 2-m air temperature and soil moisture variance from the diagnostic model are consistent with those from the products from which it was derived, although the diagnostic model generally underpredicts soil moisture variance. We use the diagnostic model to quantify the impact of soil moisture, shortwave radiation, and precipitation anomalies on temperature variance in wet and dry regions. Consistent with other studies, we find that fluctuations in soil moisture amplify temperature variance in dry regions through their impact on latent heat flux, whereas in wet regions temperature variability is muted because of high mean evapotranspiration rates afforded by plentiful surface soil moisture. We demonstrate how the diagnostic model can be used to identify sources of temperature variance bias in climate models.
\end{abstract}

\section{Introduction}

In the midlatitudes, society and agricultural production are adapted to a summer climate with monthly averaged surface temperature variance of approximatively $2 \mathrm{~K}^{2}$ (Fig. 1), roughly 3 times smaller than in the wintertime climate (Vidale et al. 2007). Schär et al. (2004) noted in their simulations that the variance in surface temperature over parts of Europe would double by the end of the twenty-first century. Their findings were robust across several greenhouse gas scenarios and global climate models. Vidale et al. (2007) came to similar conclusions with a similar set of simulations. Using a multimodel ensemble, Weisheimer and Palmer (2005) found that extremely warm summers are expected to be $50 \%$ more frequent in central North America at the end of the twenty-first century than in the twentieth century. An interesting point noted by these authors was that the

\footnotetext{
${ }^{\text {a }}$ Current affiliation: Plotly.com, Montreal, Quebec, Canada.

${ }^{\mathrm{b}}$ Current affiliation: Department of Earth and Space Science, University of Washington, Seattle, Washington.
}

Corresponding author: Lucas R. Vargas Zeppetello, lvz7@uw. edu regions of largest temperature variability change were not collocated with regions of largest mean temperature change.

All projections noted above are based on global climate model (GCM) simulations, whose reliability is difficult to judge because global observations of land surface variables such as turbulent heat fluxes and soil moisture content are limited both by geographic coverage and temporal availability (Seneviratne et al. 2010; McColl et al. 2019). In contrast, summertime temperature variability is well observed on global scales; it is of interest to see how well the GCMs reproduce this quantity. Using an ensemble of 63 members from 25 GCMs that participated in phase 5 of the Coupled Model Intercomparison Project (CMIP5), we find that the mean across all ensemble members overestimates summertime surface temperature variance by $25 \%$ to $100 \%$ over the 1979-2008 time period in most continental locations around the globe (Fig. 2; see Table 1 for a complete list of models). Kotlarski et al. (2014) found similar biases over continental Europe in an ensemble of regional climate models.

The summertime temperature variance in the ERAInterim reanalysis (ERA-I; Dee et al. 2011), compares favorably to the observations (Fig. 3, top) except for 


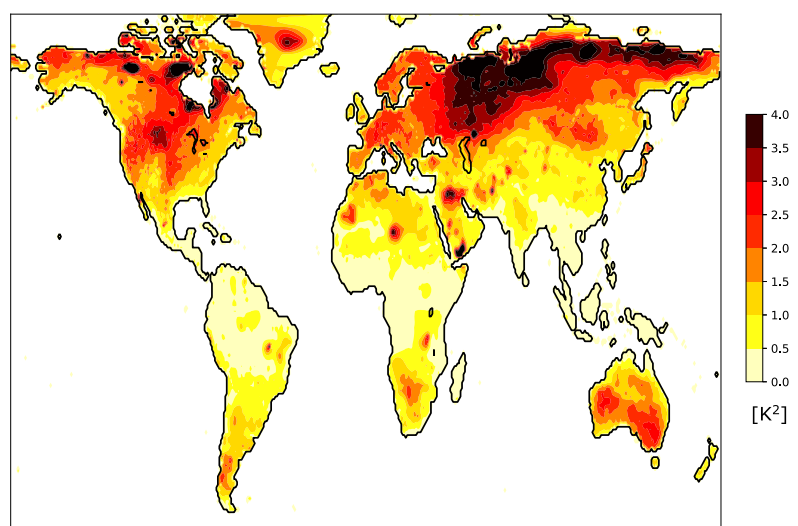

FIG. 1. Summertime variance of observed monthly averaged 2-m air temperature, $\sigma^{2}(T)$, derived from the Matsuura (2001) dataset. Throughout this study, summer is defined as June-August (JJA) in the Northern Hemisphere and December-February (DJF) in the Southern Hemisphere. Each month has its annual mean value removed when calculating the variance to remove the seasonal cycle's influence.

tropical regions, where the reanalysis product underpredicts temperature variance. In contrast, the variance in the HadCM3 GCM (Tett et al. 2007) exceeds that observed in most land areas (Fig. 3, bottom). There are widespread areas at nearly all latitudes where the summer 2-m air temperature variance is $2-4$ times greater than observed. Given the GCM errors in the historical record shown in Figs. 2 and 3, it is not clear how to interpret the large increases in interannual summertime temperature variability projected by these GCMs over the next century.

In steady state, the net radiative energy inflow to the surface is balanced by turbulent fluxes of sensible and latent heat from the surface to the atmosphere and by a smaller flow of heat down into the soil column. The surface temperature fluctuation produced by an external radiative flux perturbation thus depends on the processes governing the ensuing perturbations in energy fluxes. While a number of surface characteristics can

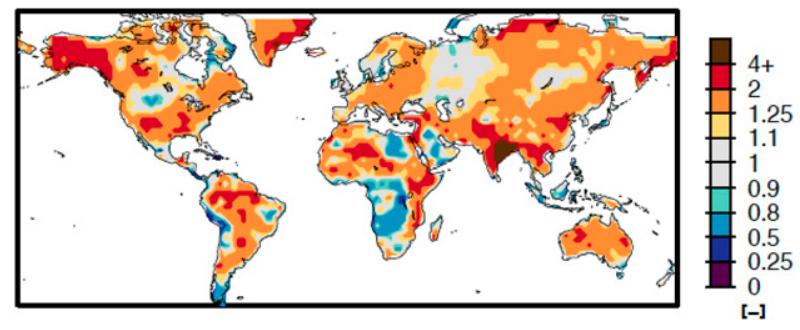

FIG. 2. Ratio of the ensemble average variance in summer average monthly 2-m air temperature from the CMIP5 GCMs to the observed temperature variance (see Fig. 1). The model output is taken from the historical runs of the CMIP5 GCMs over the same period as the observed variance: 1979-2008. See Table 1 for a list of models.
TABLE 1. Climate models used in calculating ensemble averaged monthly averaged surface temperature variance.

\begin{tabular}{ll}
\hline \multicolumn{1}{c}{ Institution } & \multicolumn{1}{c}{ Climate model } \\
\hline CSIRO (Australia) & ACCESS1.3, CSIRO-Mk3.6.0 \\
NCAR (United States) & CCSM4.0 \\
CNRM (France) & CNRM-CM5 \\
Environment and Climate & CanESM2 \\
Change Canada & \\
GFDL (United States) & GFDL CM3, GFDL-ESM2G \\
& GFDL-ESM2M \\
Hadley Centre (United & HadCM3, HadGEM2-AO \\
Kingdom) & HadGEM2-CC, \\
& HadGEM2-ES \\
IPSL (France) & CM5A-LR \\
MIROC (Japan) & MIROC5, MIROC4h \\
& MIROC-ESM-CHEM, \\
& MIROC-ESM \\
MPI (Germany) & MPI-ESM-LR, MPI-ESM-MR \\
& MPI-ESM-P \\
MRI (Japan) & CGCM3 \\
NCC (Norway) & NorESM1-M, NorESM1-M \\
BCC (China) & BCC-CSM1.1 \\
INM (Russia) & INM-CM4 \\
\hline
\end{tabular}

modulate these energy fluxes, earlier findings suggest that soil moisture is key because it regulates the partitioning of radiative perturbations between sensible and latent heat fluxes (Guo et al. 2006; Koster et al. 2006a,b; Seneviratne et al. 2010; Dirmeyer 2011). Orth and Seneviratne (2017) showed that soil moisture and sea surface temperature variability are similarly important to summertime land surface temperatures in a modern GCM.

Several authors analyzing simulations with freely evolving and constant (climatological mean) soil moisture have come to the conclusion that soil moisture fluctuations lie at the root of both the contemporary patterns of temperature variance and the increases in temperature variance projected by GCMs under increasing $\mathrm{CO}_{2}$ emissions (Seneviratne et al. 2006; Fischer et al. 2007; Seneviratne et al. 2010; Jaeger and Seneviratne 2011; Lorenz et al. 2016; Berg and Sheffield 2018). In addition, Vogel et al. (2017) argued that the large-scale drying trend in the CMIP5 ensemble simulations of business-as-usual emissions scenarios, rather than short-term soil moisture fluctuations, is primarily responsible for the increased temperature variance in those simulations.

As a demonstration of soil moisture's importance to the surface energy budget, Fig. 4 shows the correlation between monthly anomalies in latent heat flux $\mathrm{LE}^{\prime}$ and soil moisture $m^{\prime}$ from ERA-I and HadCM3 during the 1979-2008 period. The stark transition between positive and negative correlation can be explained by soil moisture's varying influence on evaporation in different climates (Vargas Zeppetello et al. 2019a). These asymmetric 

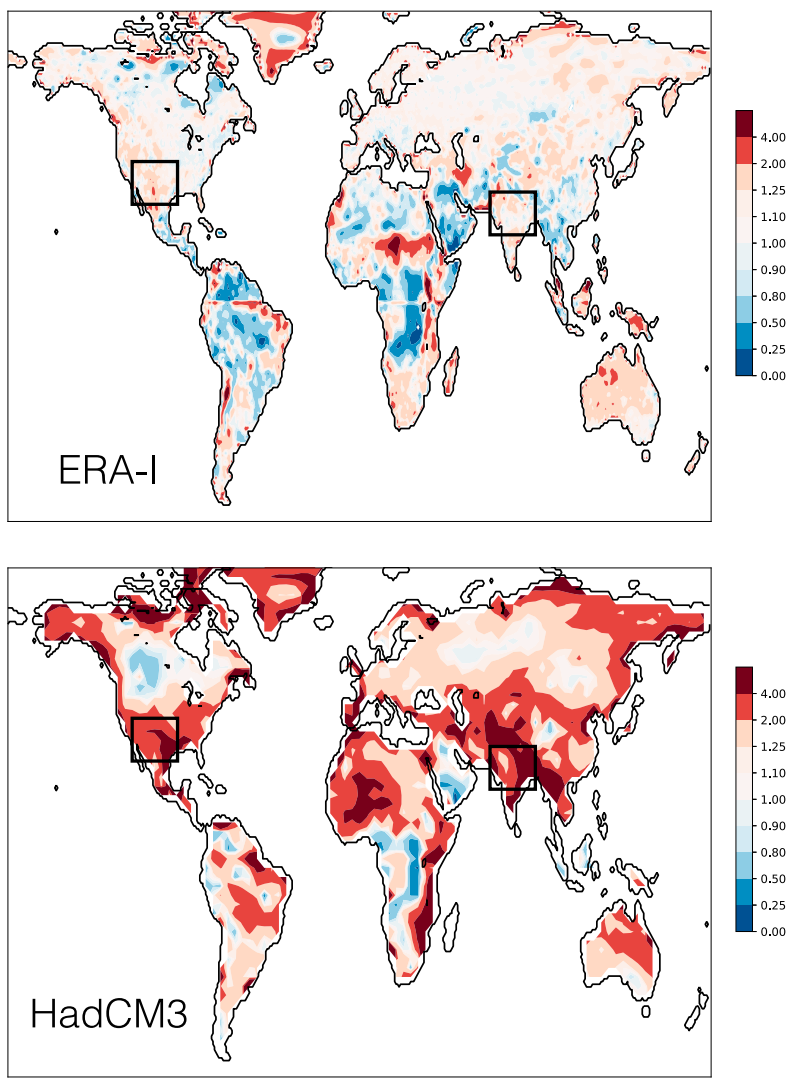

FIG. 3. Ratio of monthly averaged summertime 2-m air temperature variance in (top) ERA-I and (bottom) the HadCM3 model to the observed temperature variance for the period 1979 2008 (see Fig. 1). The regions within the black boxes in the bottom panel are further analyzed in section 5 .

soil moisture impacts on evaporation have led to the definition of "moisture limited" and "energy limited" regimes that are distinguished by a critical value of soil moisture $m_{\text {crit }}$ shown by the green line in Fig. 4 . This critical value of soil moisture at which the correlation values in both ERA-I and HadCM3 switch abruptly from positive to negative is nearly equal to the globally averaged value of summertime $m$ in those products. These apparent regimes have been observed in local flux tower analyses (Ryu et al. 2007); Teuling et al. (2009) conducted a global synthesis of available observations and found similar results but not such a stark transition between wet and dry climates.

Koster et al. (2006a) showed that the asymmetric impact of soil moisture perturbations on the surface energy fluxes in wet and dry climates across the United States is fundamental to the spatial distribution of summertime temperature variance, and Koster et al. (2015) showed that observations across the United States support a strong relationship between variance in moisture-mediated evapotranspiration and variance in temperature. These findings lead to the following hypothesis:
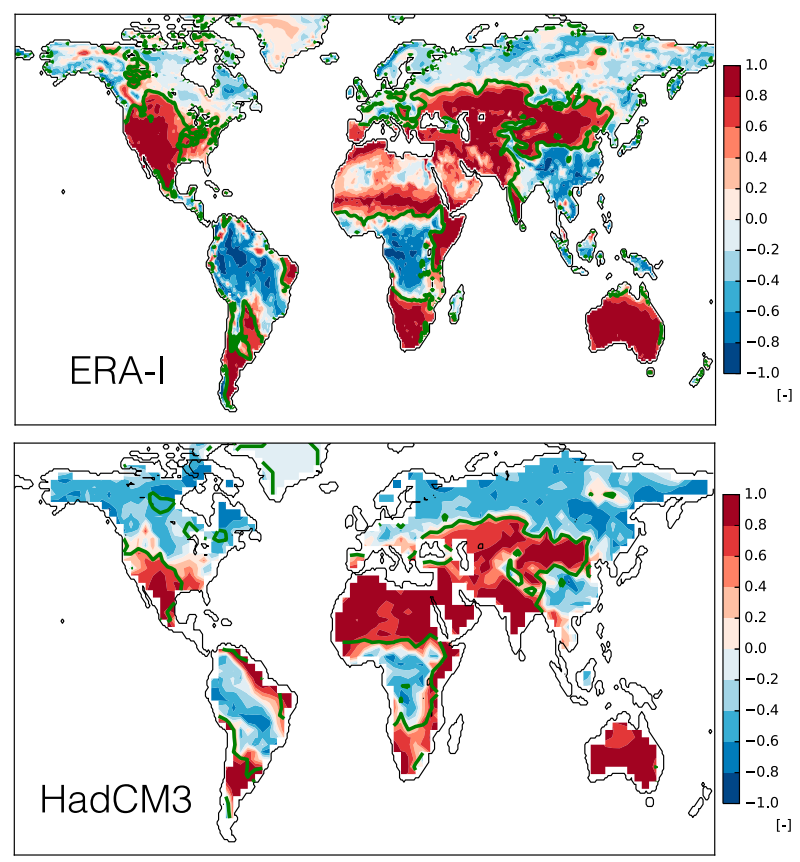

FIG. 4. Correlation of $E^{\prime}$ and $m^{\prime}$ in summertime for ERA-I and HadCM3. Correlations are calculated for each of the three summer months separately, and then averaged. Superposed is the contour line where the climatological summertime surface soil moisture is equal to the global mean surface soil moisture $\bar{m}_{G}$ for each dataset.

The biases in 2-m air temperature variance shown in Figs. 2 and 3 are due to errors in the model representations of the connection between surface turbulent energy fluxes and soil moisture.

In this paper, we take a first step toward addressing this hypothesis with the aid of our "toy model" of landatmosphere interaction on monthly time scales, developed in sections 2 and 3. For more details on model development, see Tétreault-Pinard (2013). The model quantitatively links the variance in 2-m air temperature $T$ and soil moisture $m$ to the variance in radiative forcing $\mathscr{F}$ and precipitation $\mathscr{P}$ by parameterizing anomalies in surface energy and moisture fluxes in terms of these four variables. In section 4 we use the toy model to provide a quantitative assessment of the various processes that contribute to summertime temperature variability in ERA-I. In section 5 we illustrate how the toy model can be used to identify the sources of biases in summertime temperature variance in HadCM3, one model participating in the CMIP5 project. A discussion and conclusions are presented in section 6.

\section{Model structure}

\section{a. Surface energy and moisture budgets}

In equilibrium, the land surface energy and water budgets can be written as 


$$
0=\mathscr{F}_{\mathrm{SW}}^{\prime}+F_{\downarrow \mathrm{LW}}^{\prime}-F_{\uparrow \mathrm{LW}}^{\prime}-\mathrm{LE}^{\prime}-H_{s}^{\prime}-G^{\prime},
$$

and

$$
0=\mathscr{P}^{\prime}-E^{\prime}-R^{\prime}-I^{\prime},
$$

where $\mathscr{F}_{\mathrm{sw}}\left(\mathrm{W} \mathrm{m}^{-2}\right)$ is the net absorbed shortwave radiation at the surface, $F_{\downarrow \mathrm{LW}}\left(\mathrm{Wm}^{-2}\right)$ is the downward longwave radiation incident at the surface, $F_{\uparrow \mathrm{LW}}\left(\mathrm{W} \mathrm{m}^{-2}\right)$ is the flux of longwave radiation emitted by the surface, and $\mathrm{LE}$ and $H_{s}\left(\mathrm{~W} \mathrm{~m}^{-2}\right)$ are the turbulent fluxes of latent heat and sensible heat from the surface to the atmosphere, where $L\left(\mathrm{~J} \mathrm{~m}^{-2} \mathrm{~mm}^{-1}\right)$ is the latent heat of evaporation of water. Also, $\mathscr{P}\left(\mathrm{mm} \mathrm{s}^{-1}\right)$ is the flux of precipitation to the surface, $E\left(\mathrm{~mm} \mathrm{~s}^{-1}\right)$ is the net flux of water vapor to the atmosphere due to evapotranspiration, and $R\left(\mathrm{~mm} \mathrm{~s}^{-1}\right)$ is the loss of water through runoff; $G\left(\mathrm{~W} \mathrm{~m}^{-2}\right)$ and $I$ $\left(\mathrm{mm} \mathrm{s}^{-1}\right)$ represent, respectively, the flux of energy and water from the soil surface layer into the ground below. The scripted terms in Eqs. (1) and (2) denote components of the energy budget that are assumed independent from the land-atmosphere interactions considered by the toy model. We decompose each variable $X_{i, j}$, measured in year $i$ and averaged over month $j$ (June, July, or August in the Northern Hemisphere; December, January, or February in the Southern Hemisphere) in a given grid box into a climatological mean for that month, $\bar{X}_{j}$, and a monthly averaged fluctuation $X_{i, j}^{\prime}=X_{i, j}-\bar{X}_{j}$.

\section{b. Representation of surface fluxes}

We use output from ERA-I and HadCM3 to parameterize all terms in the surface energy and water budgets in terms of state variables (temperature and soil moisture) or independent forcings (radiation and precipitation). By substituting these parameterizations into Eqs. (1) and (2), we arrive at equations for monthly temperature and soil moisture anomalies written in terms of the independent forcings. In an objective procedure, the combination of variables $(\mathscr{F}, \mathscr{P}, T$, and $m$ ) chosen for each parameterization explains more variance in the surface flux under consideration than any other combination of variables (see appendix).

Since Eq. (1) describes the surface energy budget, skin temperature suggests itself as a relevant state variable. However, to compare between global observations, models, and reanalysis we choose 2-m air temperature $T$ to be our representative temperature. Recent work (e.g., Gallego-Elvira et al. 2016; Panwar et al. 2019) has shown that surface turbulent heat fluxes impact surface and 2-m air temperature differently. However, skin and 2-m air temperature output by ERA-I are extremely well correlated $(r>0.95)$ on monthly time scales over nearly all global land surfaces in summertime. The high correlation between skin and 2-m air temperature suggests that they are functionally equivalent for parameterizing the various terms in Eqs. (1) and (2) in terms of model state variables. Parameterizing the fluxes in terms of skin temperature did not substantially alter the results that we present in this paper.

We choose our soil moisture value $m$ to be the equivalent moisture height $\left(\mathrm{mm} \mathrm{H}_{2} \mathrm{O}\right)$ in the upper $10 \mathrm{~cm}$ of soil. This is a standard model output from the CMIP5 models and can be calculated from ERA-I by interpolating appropriately weighted soil moisture output in top two vertical levels. Using this value allows us to sidestep differences between model representations of the soil column, particularly the number of soil moisture layers. More importantly, upper-level soil moisture is a primary control on surface energy fluxes, suggesting that the diagnostic model will explain more variance in these energy budget terms if surface soil moisture is used rather than a full-column value (Seneviratne et al. 2010).

Our model examines month-to-month variability and does not include temperature memory. Analysis of the HadCM3 shows that in the mid- and high latitudes, 2-m air temperature has some memory on time scales longer than one month (explaining up to $25 \%$ of the variance), but this memory is not as pronounced in observations or ERA-I (explaining less than $15 \%$ of the variance). This exaggerated temperature memory in GCMs might be linked to exaggerated soil moisture memory (see McColl et al. 2019) but we do not pursue that problem in this paper. Although feedbacks between surface fluxes, radiative forcing, and precipitation have been documented in reanalysis datasets (e.g., Findell et al. 2011), we assume that the physical processes that generate such feedbacks operate at scales larger than a climate model grid box and are therefore not relevant to our column approach.

\section{c. Surface longwave radiation}

We assume that all anomalies in surface upward longwave radiation $F_{\uparrow L W}^{\prime}$ are driven by temperature perturbations via the Planck feedback. Thus, $F_{\uparrow \mathrm{LW}}^{\prime}=\gamma_{P} T^{\prime}$, where $\gamma_{P}=4 \sigma \bar{T}^{3}$ for each grid box. On the time scales of interest in this study, anomalies in net downward longwave radiation at the surface $F_{\downarrow L W}^{\prime}$ are composed of an independent downward longwave forcing component (e.g., a change in cloudiness) given by $\mathscr{F}_{\downarrow L W}^{\prime}$, and by a response to near-surface temperature changes given by $\gamma_{\mathrm{DLR}} T^{\prime}$. We assume that any temperature anomaly $T^{\prime}$ is constant through a typical boundary layer depth and use the radiative kernels from Previdi (2010) to compute $\gamma_{\mathrm{DLR}}$, the downward longwave radiative response to a boundary layer warming of $1 \mathrm{~K}$. These assumptions have 
been used to accurately predict the downward longwave radiation response to greenhouse warming (Vargas Zeppetello et al. 2019b). With this assumption about the longwave response to temperature fluctuations, we can separate the downward longwave flux at the surface into the response to this temperature anomaly and the independent component of the downward longwave forcing $\mathscr{F}^{\prime}{ }_{\downarrow \mathrm{LW}}$ :

$$
F_{\downarrow \mathrm{LW}}^{\prime}=\mathscr{F}_{\downarrow \mathrm{LW}}^{\prime}+\gamma_{\mathrm{DLR}} T^{\prime} .
$$

The typical midlatitude value for $\gamma_{\text {DLR }}$ is $\sim 3 \mathrm{~W} \mathrm{~m}^{-2} \mathrm{~K}^{-1}$; this represents a considerable reduction of the Planck feedback $\left(\gamma_{P}=4 \sigma \bar{T}^{3} \sim 5 \mathrm{~W} \mathrm{~m}^{-2} \mathrm{~K}^{-1}\right)$.

Using Eq. (3), we can write the surface energy balance [Eq. (1)] as

$$
0=\mathscr{F}^{\prime}-\left(\gamma_{P}-\gamma_{\mathrm{DLR}}\right) T^{\prime}-\mathrm{LE}^{\prime}-H_{s}^{\prime}-G^{\prime},
$$

where $\mathscr{F}^{\prime}$ is the total radiative forcing:

$$
\mathscr{F}^{\prime} \equiv \mathscr{F}_{\mathrm{SW}}^{\prime}+\mathscr{F}_{\downarrow \mathrm{LW}}^{\prime} \cdot
$$

As noted above, the scripted terms denote components of the energy budget that are assumed independent from the land-atmosphere interactions considered by the toy model.

\section{Parameterization of the fluxes of moisture and energy}

We parameterize a monthly averaged flux perturbation $X^{\prime}$ in terms of the linear combination of at most two perturbations in the underlying variables:

$$
X^{\prime}=a Y^{\prime}+b Z^{\prime}+X_{o}^{\prime} .
$$

Here $Y^{\prime}$ and $Z^{\prime}$ are fluctuations in either the state variables $m^{\prime}, T^{\prime}$ or in the external forcings $\mathscr{F}^{\prime}, \mathscr{P}^{\prime}$, while the coefficients $a, b$ vary by grid box and depend on the month. The values $X^{\prime}, Y^{\prime}, Z^{\prime}$ are taken from HadCM3 or ERA-I output. The orthogonal projection method (see appendix) selects the coefficients $a, b$ and variables $Y^{\prime}$, $Z^{\prime}$ for which the residual variance $\sigma^{2}\left(X_{o}\right)$ is minimized. This orthogonal projection method to select the "optimum" parameterization is objective in the sense that we chose the (at most two) state variables that reduce the parameterization's unexplained variance, and that the components associated with variables $Y^{\prime}$ and $Z^{\prime}$ are linearly independent.

The orthogonal projection method does not provide a mechanistic description of the physics that govern the processes it represents. Rather, it minimizes the variance left unexplained by the parameterizations based on the state variables provided for analysis. As such, the toy model cannot prove the existence of causal relationships; our model's parameterizations should be considered as explainers of variance rather than descriptions of physical mechanisms. We now provide the formulas used in the toy model provided by the orthogonal projection method.

\section{a. Forcing decomposition}

The forcings $\mathscr{\mathscr { F }}^{\prime}$ and $\mathscr{P}^{\prime}$ are not independent; they are anticorrelated over land nearly everywhere due to the presence of thick, precipitating clouds. Since precipitation anomalies are a strong predictor of radiative forcing anomalies, it is ideal to separate the radiative forcing associated with precipitation from the radiative forcing orthogonal to precipitation anomalies:

$$
\mathscr{F}^{\prime}=\mathscr{F}^{\prime}{ }_{o}-L \alpha \mathscr{P}^{\prime} .
$$

Equation (7) defines $\mathscr{F}_{o}^{\prime}$ as the downward radiative forcing anomaly when there are no rain clouds in the sky. Thus precipitation has two impacts on the toy model: it diminishes the total radiative forcing and moistens the surface. The coefficient $\alpha$ is dimensionless and positive in all regions with significant rainfall. The orthogonal projection method described above ensures that $\mathscr{\mathscr { F }}_{o}^{\prime}$ and $\mathscr{P}^{\prime}$ are linearly independent. We refer to $\widetilde{\mathscr{F}}^{\prime}{ }_{o}$ as "nonprecipitating" and $L \alpha \mathscr{P}^{\prime}$ as "precipitating" radiative forcing in the rest of this paper. Separating the forcings in this way allows the toy model to fully reflect the role of precipitation in both modifying surface hydrology and the surface energy balance through its influence on radiative forcing.

\section{b. Ground heat and water fluxes}

Neither ERA-I nor HadCM3 provides output of ground heat flux, so we assume $G^{\prime}$ is equal to the monthly residual of the other components in Eq. (4). The simplest approximation is that fluctuations in ground heat flux are linearly proportional to surface temperature fluctuations:

$$
G^{\prime}=\gamma_{\downarrow} T^{\prime},
$$

where the coefficient $\gamma_{\downarrow}\left(\mathrm{W} \mathrm{m}^{-2} \mathrm{~K}^{-1}\right)$ is always positive. Neither this nor any other parameterization of $G^{\prime}$ explained more than $50 \%$ of the variance anywhere in HadCM3 or ERA-I, and parameterizing this flux in terms other variables $\left(\mathscr{P}^{\prime}, \mathscr{F}^{\prime}\right.$, or $\left.m^{\prime}\right)$ did not substantially increase the variance explained by Eq. (8). However, $G^{\prime}$ is a small contribution to the surface energy budget in both products, so this is not particularly concerning. 
As with ground heat flux, ERA-I and HadCM3 do not provide output of infiltration, so it is calculated as the residual of terms in Eq. (2). Infiltration of moisture into the ground is an important component of the surface water budget. Including both soil moisture and precipitation in our parameterization of infiltration proved to increase the variance explained by the parameterization:

$$
I^{\prime}=\nu_{\downarrow} m^{\prime}+\beta_{\downarrow} \mathscr{P}^{\prime} .
$$

Although $m^{\prime}$ and $\mathscr{P}^{\prime}$ are correlated, the orthogonal projection method ensures that each component of the parameterization is linearly independent from the other. Note that the dependence of the flux on two correlated variables (here $\mathscr{P}^{\prime}$ and $m^{\prime}$ ) introduces some ambiguity in the value of the coefficients (here, $\nu_{\downarrow}$ and $\beta_{\downarrow}$ ) since they depend on the order that the projections are done, as discussed in the appendix. Both the rate $\nu_{\downarrow}\left(\mathrm{s}^{-1}\right)$ and the unitless coefficient $\beta_{\downarrow}$ are positive definite.

We parameterize runoff $R$ as

$$
R^{\prime}=\beta_{R} \mathscr{P}^{\prime} .
$$

This parameterization generally explains little of the runoff variance, and adding more variables did not improve it substantially. However, $R^{\prime}$ is a small contribution to the surface water budget in both products, so this parameterization's weakness is not a major concern.

The coefficients $\beta_{\downarrow}, \beta_{R}$ in Eqs. (9) and (10) are unitless and generally take on values between zero and one. However, in high latitudes where snowmelt can exceed precipitation in the summer months, the $\beta=\beta_{\downarrow}+\beta_{R}$ value can exceed one.

\section{c. Surface sensible heat flux}

The turbulent flux of sensible heat is parameterized as

$$
H_{s}^{\prime}=\gamma_{H} T^{\prime}-L \delta_{H} \mathscr{P}^{\prime},
$$

where the coefficient $\gamma_{H}\left(\mathrm{~W} \mathrm{~m}^{2} \mathrm{~K}^{-1}\right)$ is a positive number representing the flux response to a near-surface change in temperature. The $\delta_{H}$ coefficient is dimensionless and positive in all regions with significant rainfall. Similar to the decomposition of radiative forcing [Eq. (7)], the magnitude of $\delta_{H}$ reflects the energetic constraint on sensible heat flux that is associated with monthly anomalies in shortwave radiation that accompany monthly anomalies in cloudiness, which we assume are linearly proportional to precipitation fluctuations $\mathscr{P}^{\prime}$. Further, in dry regions, precipitation increases the amount of energy partitioned into evapotranspiration by providing more soil moisture to the land surface, thereby reducing the sensible heat flux (see section 3d). Equation (11) does not imply that precipitation fluctuations physically drive changes in the sensible
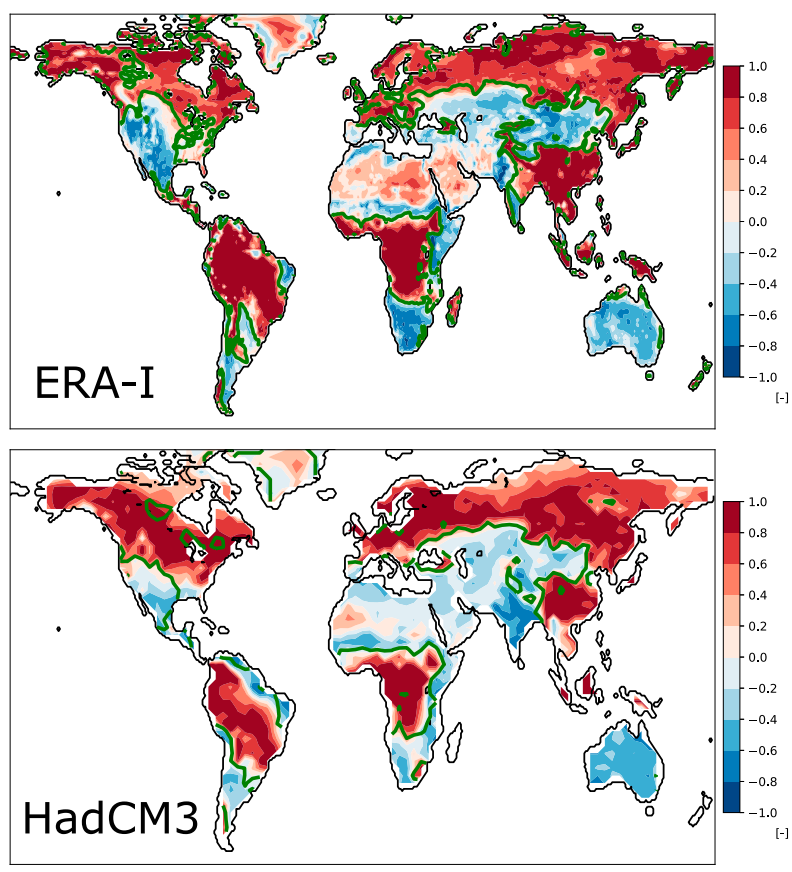

FIG. 5. As in Fig. 4, but for the correlation of $E^{\prime}$ and $\mathscr{F}^{\prime}$.

heat flux; rather, the precipitation fluctuations contain information about sensible heat flux variability that is linearly separable from temperature fluctuations by the orthogonal projection method.

\section{d. Evapotranspiration: Two parameterization regimes}

The impact of soil moisture fluctuations on evapotranspiration changes depending on the mean state soil moisture (see section 1). Thus, our parameterization of evapotranspiration must be more subtle than those for the other fluxes. Figure 4 shows the correlation between monthly anomalies in surface soil moisture $m^{\prime}$ and evapotranspiration $E^{\prime}$; superimposed on this plot is the contour line of each dataset's global average surface soil moisture, $\bar{m}_{G}$. A clear change in behavior is evident depending on whether a particular grid box's climatological soil moisture is less or greater than $\bar{m}_{G}$. While this is likely a coincidence, the presence of such a stark shift in correlation across wet and dry climates is not limited to the models considered here (e.g., Lorenz et al. 2012; Schwingshackl et al. 2017; Berg and Sheffield 2018).

In both ERA-I and HadCM3, $E^{\prime}$ and $m^{\prime}$ are highly positively correlated in regions where $\bar{m} \leq \bar{m}_{G}\left[r\left(E^{\prime}, m^{\prime}\right)>0.6\right]$ and negatively or poorly correlated in regions where $\bar{m}>\bar{m}_{G}\left[-0.8<r\left(E^{\prime}, m^{\prime}\right)<-0.2\right]$. Figure 5 shows that the dramatic shift in behavior across the global mean value of soil moisture is also reflected in the correlation between $E^{\prime}$ and radiative forcing anomalies $\mathscr{Y}^{\prime}$. In regions 
where $\bar{m}>\bar{m}_{G}$, an increase in $\mathscr{F}^{\prime}$ is associated with an increase in $E^{\prime}\left[r\left(E^{\prime}, \mathscr{F}^{\prime}\right)>0.8\right]$, indicating that radiative forcing is the primary driver of evapotranspiration in regions where soil moisture is plentiful. In dry regions $\left(\bar{m}<\bar{m}_{G}\right)$ where evapotranspiration is tightly constrained by available soil moisture, an increase in $\mathscr{F}^{\prime}$ is associated with a soil drying that drives a decrease in $E^{\prime}\left[-0.8<r\left(E^{\prime}, \mathscr{F}^{\prime}\right)<-0.2\right]$.

The development of our toy model is guided by the behavior in ERA-I and HadCM3. As two different patterns are evident in Figs. 4 and 5, we use the orthogonal projection method to generate two different parameterizations of evapotranspiration in dry and wet climates:

- Dry regions, where $\bar{m}<\bar{m}_{G}$ : The optimal parameterization can be expressed as a linear combination of fluctuations in $m^{\prime}$ and $\mathscr{F}^{\prime}$ :

$$
E_{\mathrm{dry}}^{\prime}=\nu_{E} m^{\prime}+\frac{\lambda}{L} \mathscr{F}^{\prime}
$$

where $\lambda$ is a unitless coefficient generated by projecting the residual $E^{\prime}-\nu_{E} m^{\prime}$ onto $\mathscr{\Re}^{\prime} / L$.

The rate $\nu_{E}\left(\mathrm{~s}^{-1}\right)$ is positive definite. This parameterization captures the fact that evapotranspiration variability in dry regions is a strong function of soil moisture fluctuations but is also limited by variations in the energy supply. While $\lambda$ is small in dry regions $\lambda<0.3$ and soil moisture is the fundamental control on evapotranspiration, omitting radiation in Eq. (12) increases the variance left unexplained by this parameterization.

- Wet regions, where $\bar{m} \geq \bar{m}_{G}$ : The optimal parameterization in wet regions involves only fluctuations in radiative forcing $\mathscr{\mathscr { F }}^{\prime}$ :

$$
E_{\text {wet }}^{\prime}=\frac{\lambda}{L} \mathscr{F}^{\prime}
$$

In wet regions, where radiation is the primary driver of evapotranspiration variability, $\lambda$ is in the range $0.3 \leq$ $\lambda \leq 0.7$. An alternate form of Eq. (13) that retained soil moisture as a state variable with $\nu_{E}<0$ did not increase the variance explained by the parameterization, indicating that moisture fluctuations that are linearly independent from radiation anomalies have little impact on evapotranspiration in wet regions.

We generate one set of coefficients $\left(\gamma_{P}, \gamma_{H}, \gamma_{\downarrow}, \lambda\right.$, $\left.\nu_{E}, \nu_{\downarrow}, \beta_{R}, \beta_{\downarrow}, \delta_{H}, \alpha\right)$ for each grid cell of both ERA-I and HadCM3, yielding two realizations of the toy model with different coefficients that reflect the behavior of these two different models. We found that the variance
TABLE 2. A list of the parameterization of fluxes in terms of the state variables $\left(m^{\prime}, T^{\prime}\right)$ and forcings $\left(\mathscr{F}^{\prime}, \mathscr{P}^{\prime}\right)$. The variance explained by each parameterization is indicated by the range in squared correlation between the parameterized flux and the "actual" flux, as taken from ERA-I except for runoff and infiltration, which are taken from HadCM3. For each flux, the squared correlation values for each parameterization are similar in the HadCM3 and in the ERA-I. For spatial maps of these $r^{2}$ values, see Fig. 6

\begin{tabular}{llc}
\hline \hline \multicolumn{1}{c}{ Flux } & \multicolumn{1}{c}{ Parameterization } & $\begin{array}{c}r^{2} \\
\text { (parameterized, } \\
\text { model fluxes) }\end{array}$ \\
\hline $\begin{array}{l}\text { Upward longwave } \\
\text { Sensible heat flux }\end{array}$ & $F_{\uparrow}^{\prime}=\gamma_{P} T^{\prime}$ & $0.77-0.98$ \\
Evapotranspiration & $H_{s}^{\prime}=\gamma_{H} T^{\prime}-L \delta_{H} \mathscr{P}^{\prime \prime}$ & $0.04-0.95$ \\
& $E^{\prime}=\frac{\lambda}{L} \mathscr{F}^{\prime}($ wet); & $0.17-0.98$ \\
Runoff & $E^{\prime}=\nu_{E} m^{\prime}+\frac{\lambda}{L} \mathscr{F}^{\prime}($ dry) & \\
Infiltration & $R^{\prime}=\beta_{R} \mathscr{P}^{\prime}$ & $0.00-0.32$ \\
Ground heat flux & $I^{\prime}=\nu_{\downarrow} m^{\prime}+\beta_{\downarrow} \mathscr{P}^{\prime}$ & $0.35-0.98$ \\
& $G^{\prime}=\gamma_{\downarrow} T^{\prime}$ & $0.00-0.12$ \\
\hline
\end{tabular}

explained by each flux parameterization is nearly equal in the two models considered here and three others analyzed in Tétreault-Pinard (2013). Table 2 summarizes the variance in model output explained by each parameterization. Figure 6 shows maps of variance explained by each parameterization; values for the parameterizations of $E^{\prime}$ and $H_{s}^{\prime}$ are from ERA-I, and of $R^{\prime}$ and $I^{\prime}$ from the HadCM3. Table 3 summarizes the flux parameters and their typical values, while Fig. 7 shows the spatial distribution of the toy model coefficients given by the orthogonal projection method applied to the ERA-I output.

\section{The toy model}

The toy model for 2-m air temperature and surface soil moisture is now obtained by inserting the parameterized fluxes Eqs. (8)-(12) into Eqs. (2) and (4):

$$
m^{\prime}=\frac{1}{\nu_{s}}\left[(1-\beta) \mathscr{P}^{\prime}-\frac{\lambda}{L}\left(\mathscr{F}_{o}^{\prime}-L \alpha \mathscr{P}^{\prime}\right)\right]
$$

and

$$
T^{\prime}=\frac{1}{\gamma}\left[(1-\lambda)\left(\mathscr{\mathscr { F }}_{o}^{\prime}-L \alpha \mathscr{P}^{\prime}\right)+L \delta_{H} \mathscr{P}^{\prime}-L \nu_{E} m^{\prime}\right],
$$

where $\nu_{s} \equiv \nu_{\downarrow}+\nu_{E}$ is the total rate at which water escapes from the surface layer, $\gamma \equiv \gamma_{P}+\gamma_{\downarrow}+\gamma_{H}-\gamma_{L W}$ is a "heat capacity" parameter, relating the temperature anomaly to the net energy flux into the surface layer, and $\beta \equiv \beta_{\downarrow}+\beta_{R}$ is the fractional loss of precipitation that leaves the surface layer due to downward or lateral transport (i.e., $1-\beta$ is the efficiency of 

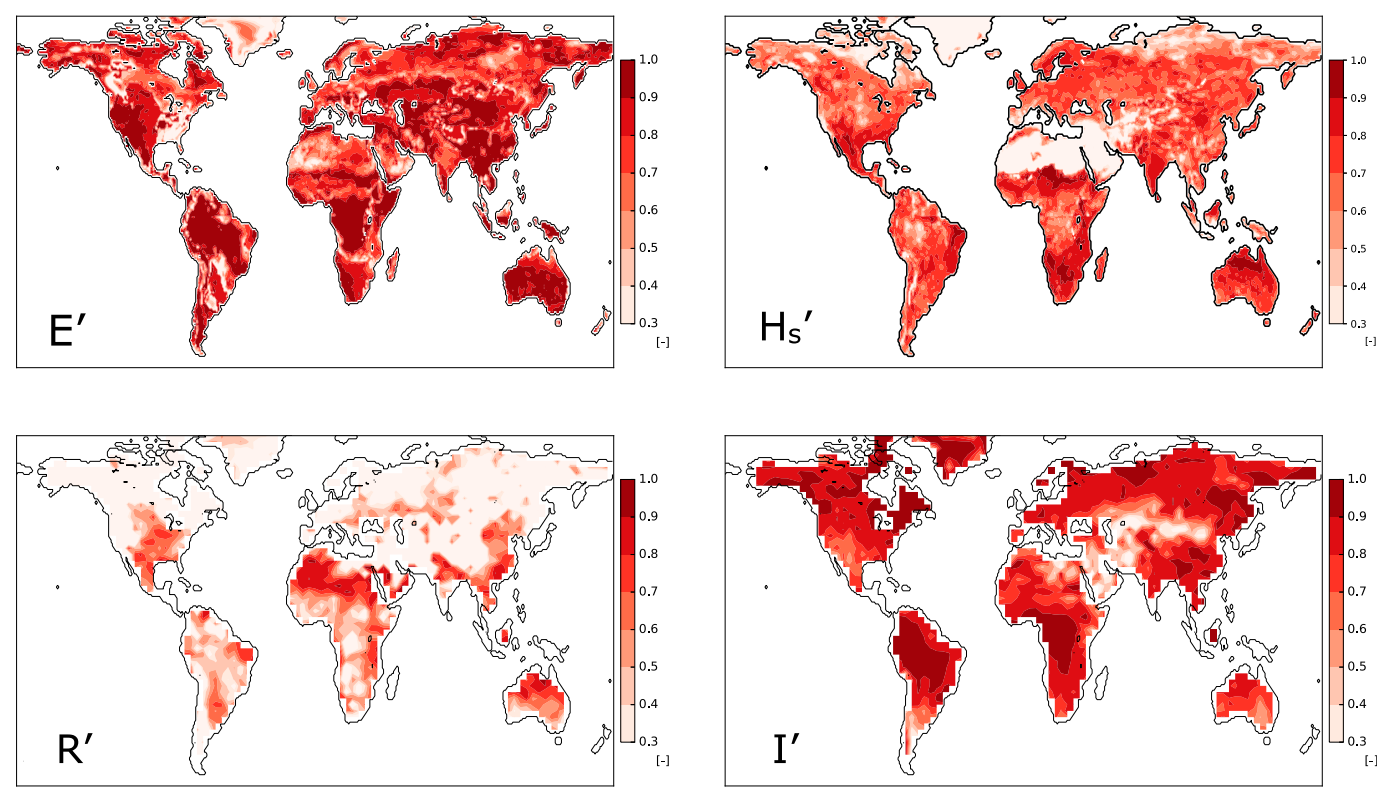

FIG. 6. The variance explained by the key parameterizations, measured by the squared correlation between the parameterized flux and the "actual" flux (i.e., that obtained from HadCM3 or ERA-I). (top) Variance explained by the parameterizations of $E^{\prime}$ and $H_{s}^{\prime}$ using ERA-I output, and (bottom) variance explained by the parameterization of $R^{\prime}$ and $I^{\prime}$ using the HadCM3 output. Runoff $R$ is not an important component of the water budget in regions where the parameterization explains a small fraction of the runoff variance. The ground heat flux $G^{\prime}$ is a negligible component of the heat budget everywhere, and our parameterization of upward longwave flux is nearly perfect everywhere; neither map is shown here.

precipitation in moistening the surface layer). In Eqs. (14) and (15), we have also used Eq. (7) to substitute $\mathscr{\mathscr { H }}^{\prime}=\mathscr{F}_{o}^{\prime}-L \alpha \mathscr{P}^{\prime}$.

Importantly, we have used 2-m air temperature as a state variable in our parameterizations of terms in the surface energy budget. This requires some justification, as sensible heat flux cools the land surface and warms the boundary layer on short time scales (see Fischer et al. 2007). However, on monthly time scales skin and 2-m air temperature are nearly perfectly correlated: a large surface temperature anomaly can drive increased sensible heat flux leading to a warming of 2-m air temperature. On monthly time scales, we treat the landatmosphere interface as a "phantom layer" with a temperature variability that is equally well represented by land surface or 2-m air temperature. Positive sensible heat flux anomalies release energy from (and cool) this layer; negative sensible heat flux anomalies indicate that the layer is retaining energy and imply a warming. Considerations of shorter time scales, where the distinction between skin and 2-m air temperature is important, are beyond the scope of this paper, and further research on short time scale energy partitioning in land surface models is needed to understand the dynamics we interpret through our diagnostic framework.
The two terms on the right-hand side (RHS) of Eq. (14) show the opposing impacts of precipitation and radiative flux on surface moisture. Positive precipitation anomalies moisten the soil directly, and are also associated with reduced evaporation (and therefore with damper soils) through their impact on radiative forcing. In contrast, positive radiative forcing anomalies contribute to soil drying through enhanced evapotranspiration. The first term on the RHS of Eq. (15) is the temperature change due to that fraction of the radiative forcing that is not used for evapotranspiration $(1-\lambda)$, the second term reflects the radiative impact of thick precipitating clouds on sensible heat flux, and the third term is the temperature fluctuation due to soil moisture's connection to latent heat flux perturbations.

Figure 8 shows a schematic summary of the model pathways that modulate temperature anomalies in response to precipitating (bottom) and nonprecipitating (top) radiative forcing. Red arrows denote direct impacts of the forcing, while blue arrows denote the impacts of soil moisture on temperature variability. The size of the arrows reflects the magnitude of the coupling between various forcings, fluxes, and state variables.

Equations (14) and (15) can be combined to yield the equation for temperature anomalies in terms of the forcing: 
TABLE 3. Summary of the flux parameters $\left(\nu_{s}, \gamma, \beta, \nu_{E}, \lambda\right)$, forcing coefficients $(\alpha, J)$, and their typical values across wet and dry regions in the ERA-I reanalysis product. Also shown is the ratio $J$ of the variance in radiative forcing associated with precipitating clouds to the variance in total radiative forcing.

\begin{tabular}{|c|c|c|}
\hline Bulk parameter & Symbol & Typical value \\
\hline Rate $\left(\right.$ day $\left.^{-1}\right)$ at which water leaves the surface layer [Eq. (14)] & $\nu_{s}=\nu_{\downarrow}+\nu_{E}$ & $0-0.5$ (dry); 0.3-0.9 (wet) \\
\hline $\begin{array}{l}\text { Thermal resistance }\left[\left(\mathrm{W} \mathrm{m}^{-2}\right) \mathrm{K}^{-1}\right] \text { to a net change in the surface } \\
\text { energy budget [Eq. (15)] }\end{array}$ & $\gamma=\gamma_{P}+\gamma_{\downarrow}+\gamma_{H}-\gamma_{\mathrm{DLR}}$ & $5-20$ \\
\hline $\begin{array}{l}\text { Fraction of precipitation (unitless) that drains from the surface } \\
\text { layer [Eq. (14)] }\end{array}$ & $\beta=\beta_{R}+\beta_{\downarrow}$ & $0.1-0.3$ (dry); 0.4-0.7 (wet) \\
\hline $\begin{array}{l}\text { Coupling coefficient linking soil moisture anomalies to latent heat } \\
\text { flux anomalies (unitless) [Eq. (16)] }\end{array}$ & $\nu_{E} / \nu_{S}$ & $0.1-0.6$ (dry); 0.0 (wet) \\
\hline $\begin{array}{l}\text { Fraction of net radiative forcing } \mathscr{F}^{\prime} \text { used for evapotranspiration } E^{\prime} \\
\quad \text { (unitless) [Eq. (12)] }\end{array}$ & $\lambda$ & $0.1-0.3$ (dry); 0.3-0.7 (wet) \\
\hline $\begin{array}{l}\text { Fraction of net radiative forcing } \mathscr{\mathscr { T }} \text { linearly congruent with } \\
\text { precipitation }-L \mathscr{P}^{\prime} \text { (unitless) [Eq. (7)] }\end{array}$ & $\alpha$ & $0.1-0.5$ \\
\hline $\begin{array}{l}\text { Fraction of precipitation forcing } \mathcal{P} \text { linearly congruent with surface } \\
\text { sensible heat flux } H_{s}^{\prime} \text { (unitless) [Eq. (11)] }\end{array}$ & $\delta_{H}$ & $0.0-0.6$ \\
\hline $\begin{array}{l}\text { Ratio of the variance in radiative forcing associated with } \\
\text { precipitating clouds to the variance in total radiative forcing }\end{array}$ & $J=\sigma^{2}(\alpha L \mathscr{P}) / \sigma^{2}(\mathscr{F})$ & $0.1-0.7$ \\
\hline
\end{tabular}

$$
\begin{aligned}
T^{\prime}= & \frac{1}{\gamma}\left(\left[1-\lambda\left(1-\frac{\nu_{E}}{\nu_{S}}\right)\right] \mathscr{\mathscr { Y }}_{o}^{\prime}-\left\{\alpha\left[1-\lambda\left(1-\frac{\nu_{E}}{\nu_{S}}\right)\right]\right.\right. \\
& \left.\left.+\frac{\nu_{E}}{\nu_{S}}(1-\beta)-\delta_{H}\right\} L \mathscr{P}^{\prime}\right) .
\end{aligned}
$$

The ratio $\nu_{E} / \nu_{S}$ measures the coupling strength between surface moisture and temperature anomalies. This fraction can be either positive or zero: our parameterization of $E^{\prime}$ ensures that when $\bar{m}>\bar{m}_{G}, \nu_{E} / \nu_{S}=0$, whereas $\nu_{E} / \nu_{S}$ is positive when a region's climatological soil moisture is less than the global mean (see Fig. 7). We now explore the impact of this coupling term on temperature fluctuations in our model.

\section{a. Coupled moisture and temperature variability in the two surface regimes}

As emphasized above, our model is diagnostic, so parsing cause and effect is not possible. However, we can construct plausible physical interpretations of the major findings by considering the temperature and soil moisture response to separate fluctuations in the external forcing, $\mathscr{F}_{o}^{\prime}$ and $\mathscr{P}^{\prime}$ [from Eqs. (14) and (16)], with and without the latent heat flux anomalies associated with moisture fluctuations (i.e., with $\nu_{E}=0$ and $\left.\nu_{E}>0\right)$.

Case 1: $\mathscr{F}_{o}^{\prime}>0, \mathscr{P}^{\prime}=0 \rightarrow m^{\prime}=-\frac{\lambda}{\nu_{s} L} \mathscr{F}^{\prime}$

$$
T^{\prime}= \begin{cases}\frac{1}{\gamma} \mathscr{\mathscr { F }}_{o}^{\prime}(1-\lambda) & \text { if } \quad \nu_{E}=0 \\ \frac{1}{\gamma} \mathscr{\mathscr { F }}_{o}^{\prime}(1-\lambda)+\frac{\nu_{E}}{\gamma \nu_{S}} \lambda \mathscr{F}_{o}^{\prime} & \text { if } \quad \nu_{E}>0 .\end{cases}
$$

We can ignore latent heat flux modifications associated with soil moisture fluctuations by setting $\nu_{E}=0$ : without these modifications, the degree of warming across regions is dependent only on the fraction of incident radiation used for evapotranspiration $\lambda$.

However, when we include the dry-region coupling between surface hydrology and the latent heat flux $\nu_{E}>$ 0 , the initial warming forced by a radiation anomaly $\mathscr{F}_{o}^{\prime}>0$ is amplified by the decrease in evapotranspiration associated with a drying soil. In contrast, the warming is muted in wet regions, because the fraction of radiative forcing used to evaporate soil moisture $\lambda$ is greater for wet than dry regions (see Fig. 7).

Case 2: $\mathscr{P}^{\prime}>0, \mathscr{\mathscr { T }}_{o}^{\prime}=0 \rightarrow m^{\prime}=\frac{1}{\nu_{s}}[\lambda \alpha+(1-\beta)] \mathscr{P}^{\prime}$

$$
T^{\prime}= \begin{cases}-\frac{1}{\gamma}\left[\alpha(1-\lambda)-\delta_{H}\right] L \mathscr{P}^{\prime} & \text { if } \quad \nu_{E}=0 \\ -\frac{1}{\gamma}\left[\alpha(1-\lambda)-\delta_{H}\right] L \mathscr{P}^{\prime}-\frac{\nu_{E}}{\gamma \nu_{S}} L \mathscr{P}^{\prime}[\lambda \alpha+(1-\beta)] & \text { if } \quad \nu_{E}>0 .\end{cases}
$$



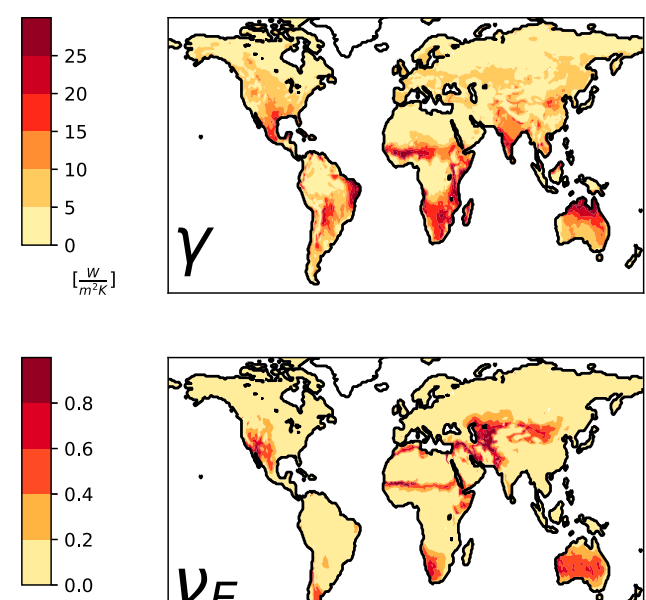

$\left[\right.$ day $\left.^{-1}\right]$
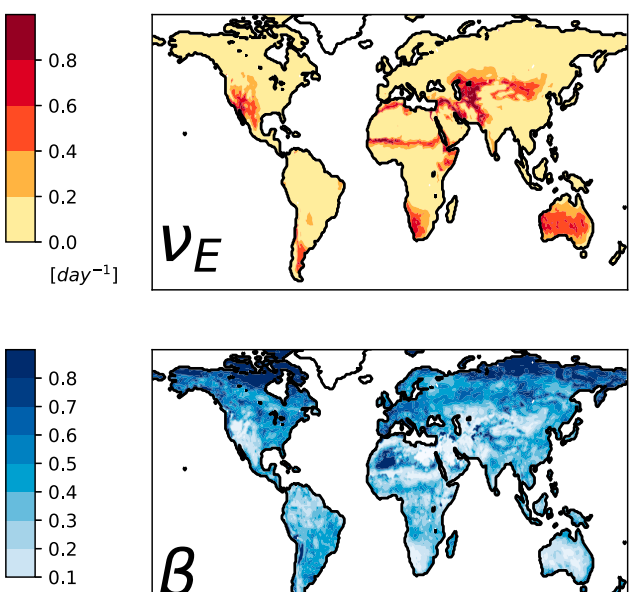

0.8
0.7
0.6
0.5
0.4
0.3
0.2
0.1
$[-]$
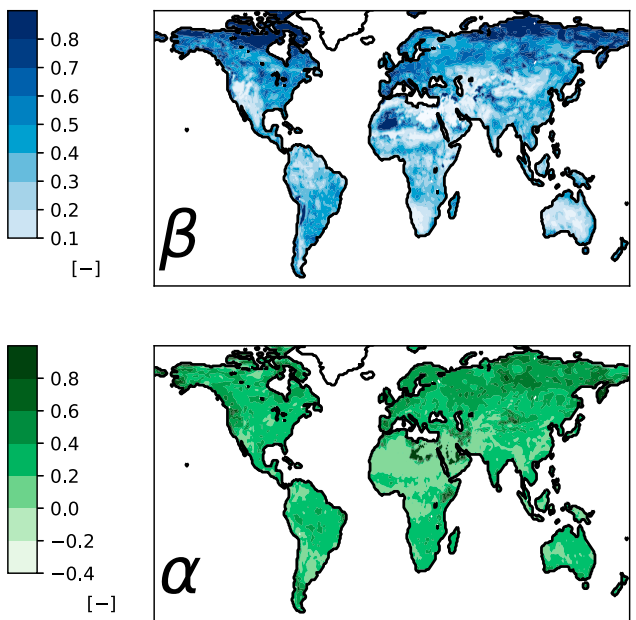
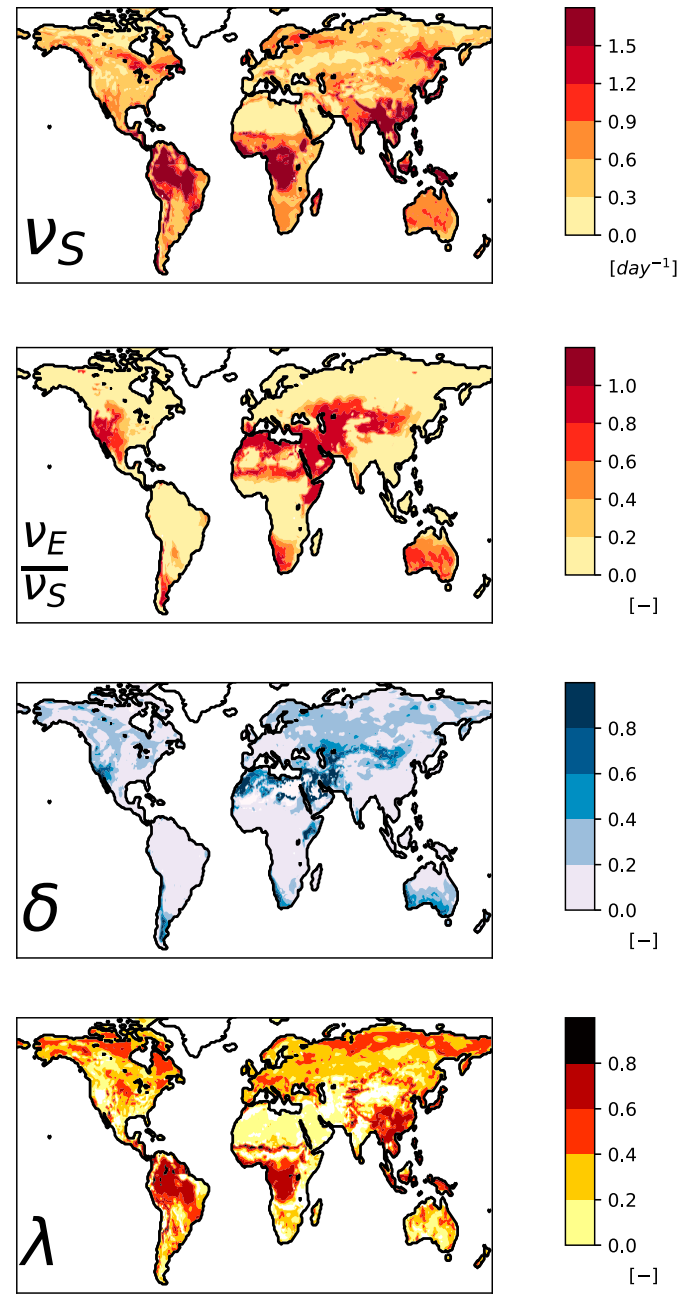

FIG. 7. The toy model coefficients determined from the flux parameterizations fit to the ERA-I output. The panels show the average value of each coefficient over the three summer months.

We first ignore all surface latent heat flux modifications associated with soil moisture perturbations by setting $\nu_{E}=0$, whereby the negative radiative forcing anomaly associated with precipitation's effect on evapotranspiration $\left[-L \alpha \mathscr{P}^{\prime}(1-\lambda)\right]$ leads to cooling opposed by a warming associated with a damped sensible heat flux $L \delta_{H} \mathscr{P}^{\prime}$. Similar to the uncoupled version of case 1 , the regional differences in this cooling are due to differences in $\lambda$ that control how much any radiative perturbation is used for evapotranspiration and $\delta_{H}$ that reflects the sensible heat flux sensitivity to radiative forcing associated with precipitating clouds. Including the moisture impact on the latent heat flux in dry regions $\left(\nu_{E}>0\right)$, the radiative cooling associated with precipitation is amplified because more soil moisture is made available for evapotranspiration by the precipitation anomaly.

To gain further insight into the switch between amplification and muting of temperature anomalies, we rewrite Eq. (16) in terms of the precipitation $\mathscr{P}^{\prime}$ and net radiative forcing $\mathscr{\mathscr { H }}^{\prime}$ :

$$
T^{\prime}=\frac{1}{\gamma}\left\{\left[1-\lambda\left(1-\frac{\nu_{E}}{\nu_{S}}\right)\right] \mathscr{F}^{\prime}-\left[\frac{\nu_{E}}{\nu_{S}}(1-\beta)-\delta_{H}\right] L \mathscr{P}^{\prime}\right\}
$$

Since $\lambda>0$, the first term on the RHS of Eq. (19) shows that land-atmosphere interactions amplify radiatively driven temperature anomalies in dry regions (where $\left.\nu_{E}>0\right)$ through coupling between soil moisture and evapotranspiration; in wet regions where $\lambda$ is large, the efficacy of radiative forcing to generate temperature anomalies is reduced compared to dry regions because more of the energy coming into the system is used to evaporate liquid water. The second term on the RHS of Eq. (19) shows that in wet regions where $\nu_{E}=0$, sensible heat flux anomalies driven by cloudiness oppose radiative 


\section{Wet Region / Land Muted}
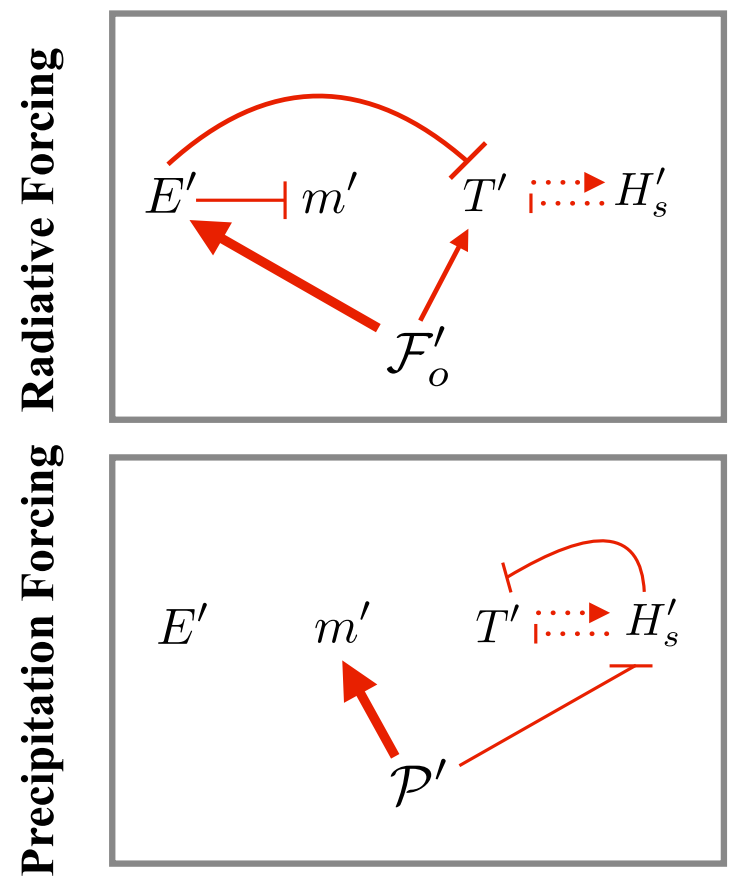

\section{Dry Region / Land Amplified}
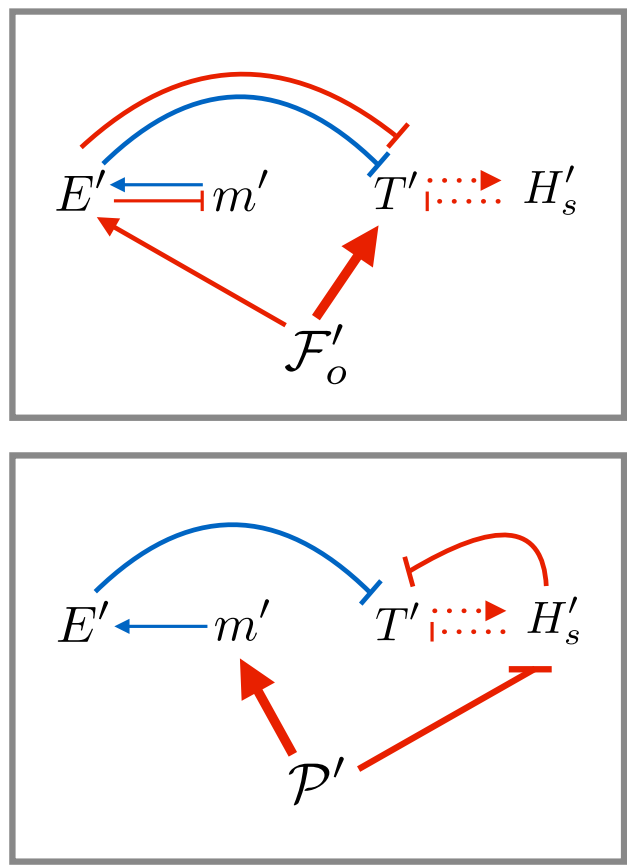

FIG. 8. Schematic showing model pathways that modulate temperature variance in (left) wet/land muted and (right) dry/land amplified regions in response to (top) nonprecipitating and (bottom) precipitating forcing. Lines with arrows and stops denote positive and negative relationships, respectively; red lines denote direct impacts of forcing and blue lines show impacts of coupling between soil moisture, latent heat flux, and temperature. Thicker lines designate primary forcing impacts, while thinner lines denote weaker relationships. The dotted lines represent the relationship between sensible heat flux and temperature that is identical in each of the four panels.

forcing anomalies (as $\mathscr{\mathscr { F }}^{\prime}$ and $\mathscr{P}^{\prime}$ are anticorrelated). This impact further mutes temperature variability in wet regions, while in dry regions where $\nu_{E}>0$, the latent heat flux modifications associated with precipitation forcing act to amplify radiative forced temperature anomalies.

\section{b. Quantifying the impact of land surface and soil moisture anomalies on temperature variability}

Next we use the toy model to estimate the difference in temperature variance in wet and dry regions, given the same forcings, $\mathscr{\mathscr { H }}^{\prime}$ and $\mathscr{P}^{\prime}$. The temperature variance $\sigma^{2}(T)$ is obtained from Eq. (19):

$$
\sigma^{2}(T)=\left[C_{0}+C_{1} \frac{\nu_{E}}{\nu_{S}}+C_{2}\left(\frac{\nu_{E}}{\nu_{S}}\right)^{2}\right] \gamma^{-2} \sigma^{2}(\mathscr{F}),
$$

where

$$
\begin{aligned}
& C_{0}=(1-\lambda)^{2}+\frac{J \delta_{H}}{\alpha}\left[\left(\frac{\delta_{H}}{\alpha}\right)-2(1-\lambda)\right], \\
& C_{1}=2\left\{(1-\lambda)\left[\lambda+(1-\beta) \alpha^{-1} J\right]-\delta_{H}\left[\lambda+(1-\beta) \alpha^{-2} J\right]\right\},
\end{aligned}
$$

$$
C_{2}=\lambda^{2}+\left[(1-\beta)^{2} \alpha^{-2}+2 \lambda(1-\beta) \alpha^{-1}\right] J,
$$

and $J=\sigma^{2}(\alpha L \mathscr{P}) / \sigma^{2}(\mathscr{F})$ is the ratio of precipitation related radiation forcing to net radiation forcing. Spatial maps of $J$ for ERA-I and HadCM3 are shown in the bottom panels of Fig. 9.

In Eq. (20), the coefficients $C_{1}$ and $C_{2}$ [see Eqs. (22) and (23)] are governed by the correlations between soil moisture and turbulent surface energy flux anomalies. Since the diagnostic model has no connection between soil moisture and latent heat flux anomalies in wet regions (where $\nu_{E}=0$ ), these two coefficients only impact the temperature variance in dry regions. In contrast, the constant term in Eq. (20) [defined in Eq. (21)] contributes to temperature variance in both wet and dry regions. The first term on the RHS of Eq. (21) is the temperature variance associated with the incoming radiative flux. Here the only difference between wet and dry areas is the value of $\lambda$, the fraction of the incoming radiation anomaly that is used for evapotranspiration rather than to increase the temperature; the impact of mean soil moisture on 

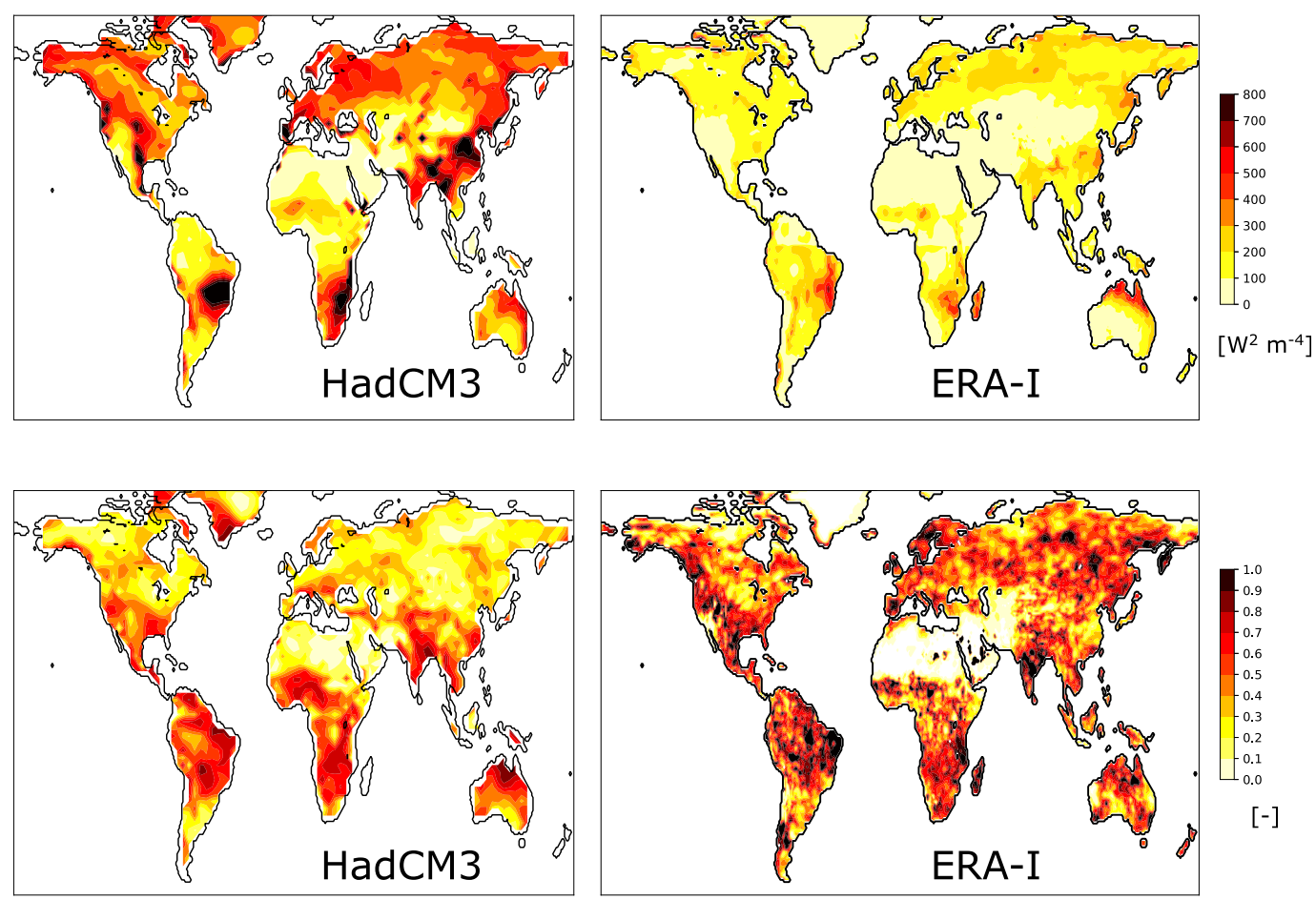

FIG. 9. (top) The variance in radiative forcing $\sigma^{2}(\mathscr{F})$ and (bottom) the ratio of variance in radiation forcing associated with precipitating clouds to variance net radiative forcing $\left[J=\sigma^{2}(L \alpha \mathscr{P}) / \sigma^{2}(\mathscr{F})\right]$.

temperature, rather than soil moisture fluctuations, is measured by this term. Previous authors (e.g., Koster et al. 2006a; Seneviratne et al. 2010; Koster et al. 2015) have invoked the processes captured in this term to describe the impacts of evapotranspiration on temperature fluctuations, and we show below that it is indeed the major contributor to the difference in temperature variance between wet and dry regions. The second term on the RHS of Eq. (21) captures the sensitivity of sensible heat flux to the precipitating component of the radiative forcing. The $\delta_{H}$ term can be conceptualized as the inverse of $\lambda$ : if a particular region uses a small fraction of incident radiation for evapotranspiration, the sensible heat flux must be extremely sensitive to variations in the precipitating component of the radiative forcing. Similarly, if $\lambda$ is large and a large fraction of radiation is used for evapotranspiration, the sensible heat flux sensitivity to the precipitating component of the radiative forcing (measured by $\delta_{H}$ ) must be low.

We now use Eq. (20) to quantify the different contributions to the temperature variance. Using typical values from ERA-I for $J$ and $\alpha$ and for the model coefficients $\lambda, \beta, \nu_{E}$, and $\nu_{S}$ in the dry (top row) and wet (bottom row) midlatitude regions (see Table 3), we find:

$$
\begin{aligned}
\sigma^{2}(T) & =\left[\begin{array}{c}
1.82-0.18 \frac{\nu_{E}}{\nu_{S}}+1.68 \frac{\nu_{E}^{2}}{\nu_{S}^{2}} \\
0.16+0.08 \frac{\nu_{E}}{\nu_{S}}+1.45 \frac{\nu_{E}^{2}}{\nu_{S}^{2}}
\end{array}\right] \times \frac{\sigma^{2}(\mathscr{F})}{\gamma^{2}} \\
& =\left[\begin{array}{l}
2.84-0.29+1.57 \\
0.25-0.00+0.00
\end{array}\right]=\begin{array}{l}
4.12 \mathrm{~K}^{2} \\
0.25 \mathrm{~K}^{2}
\end{array}
\end{aligned}
$$

where we have used nominal values for the forcing variance $\sigma^{2}(\mathscr{F}) \sim 100 \mathrm{~W}^{2} \mathrm{~m}^{-4}$ and $\gamma$ parameter $\sim 8 \mathrm{~W} \mathrm{~m}^{-2} \mathrm{~K}^{-1}$ from ERA-I (see Figs. 7 and 9). First, we note that even without considering fluctuations in turbulent energy fluxes associated with soil moisture anomalies $\left(\nu_{E}=0\right)$, the same variance in radiative forcing $\sigma^{2}(\mathscr{H})$ causes temperature variance to be more than 11 times greater $(2.84 / 0.25=11.4)$ in dry regions compared to wet regions because in wet regions a greater fraction of $\mathscr{F}^{\prime}$ $\left(\lambda_{\text {wet }}=0.5 \mathrm{vs} \lambda_{\text {dry }}=0.2\right)$ is used to evaporate water rather than heat the surface and because the surface sensible heat flux in dry regions is much more sensitive to fluctuations in the precipitating component of the radiative forcing $\left(\delta_{H \text {,dry }}=0.5\right.$ vs $\left.\delta_{H \text {,wet }}=0.2\right)$. This difference is estimated by setting $\nu_{E}=0$ in Eq. (20), whereby $\sigma^{2}(T)=\gamma^{-2} C_{0} \sigma^{2}(\mathscr{F})$. 
For conceptual purposes, we will take the first term on the RHS of Eq. (20) as the "base" variance associated with a particular land surface's partitioning of latent and sensible heat (governed by $\lambda$, or the climatological soil moisture). Including the connection between soil moisture and latent heat flux anomalies amplifies the difference in temperature variance between wet and dry regions. Including the impact of soil moisture on evapotranspiration in dry regions amplifies the temperature variance in dry regions from 2.84 to $4.12 \mathrm{~K}^{2}$. Such amplification does not exist in wet regions, where latent heat flux is insensitive to fluctuations in soil moisture.

The preceding analysis suggests that temperature variance in dry regions should be much greater than wet regions. So why is the temperature variance not greater in the dry regions, compared to the wet regions in the mid- and high latitudes? Figure 1 shows that the temperature variance in wet northern Canada is about 3 times greater than in the dry southwest United States $\left(\sim 2.5 \mathrm{~K}^{2}\right.$ compared to $\left.1 \mathrm{~K}^{2}\right)$. In many dry regions, the increased variance that we expect due to low values of $\lambda$ and the impact of soil moisture on evapotranspiration is more than compensated for by differences in forcing variance. In ERA-I, the radiative forcing in wet regions in the middle and high latitudes is on the order of $200 \mathrm{~W}^{2} \mathrm{~m}^{-4}$ (see Fig. 9) while in dry regions such as the southwest United States it is on the order of $50 \mathrm{~W}^{2} \mathrm{~m}^{-4}$ (see Table 5). Incorporating the differences in forcing amplitude and thermal inertia $\gamma$ (see Fig. 7) into Eq. (20), we obtain a temperature variance in a wet, high forcing variance region of $1.98 \mathrm{~K}^{2}$ and a dry, low forcing variance region of $1.33 \mathrm{~K}^{2}$, more similar to the observed values (see Fig. 1).

\section{c. The toy model and the twentieth-century climate in ERA-I and HadCM3}

We present two realizations of the toy model with parameters and forcings obtained both from ERA-I and HadCM3 model output. In general, the toy model's temperature variance agrees well with the ERA-I output and is a fair fit to the HadCM3 output (see Fig. 10). In the ERA-I realization of the toy model, $69 \%$ of grid cells are within a factor of 2 of the correct summertime temperature variance; in the HadCM3 realization 51\% of the grid cells are within a factor of 2 of the correct temperature variance. The toy model predicts too much temperature variance in the HadCM3 realization, particularly in the high latitudes in the Northern Hemisphere. Figure 11 shows that the toy model underpredicts soil moisture variance $\sigma^{2}(m)$ nearly everywhere in both ERA-I and HadCM3. The overprediction of soil moisture variance in the Sahara and Arabian Peninsula by the toy model fit to the ERA-I data is not of particular concern, as
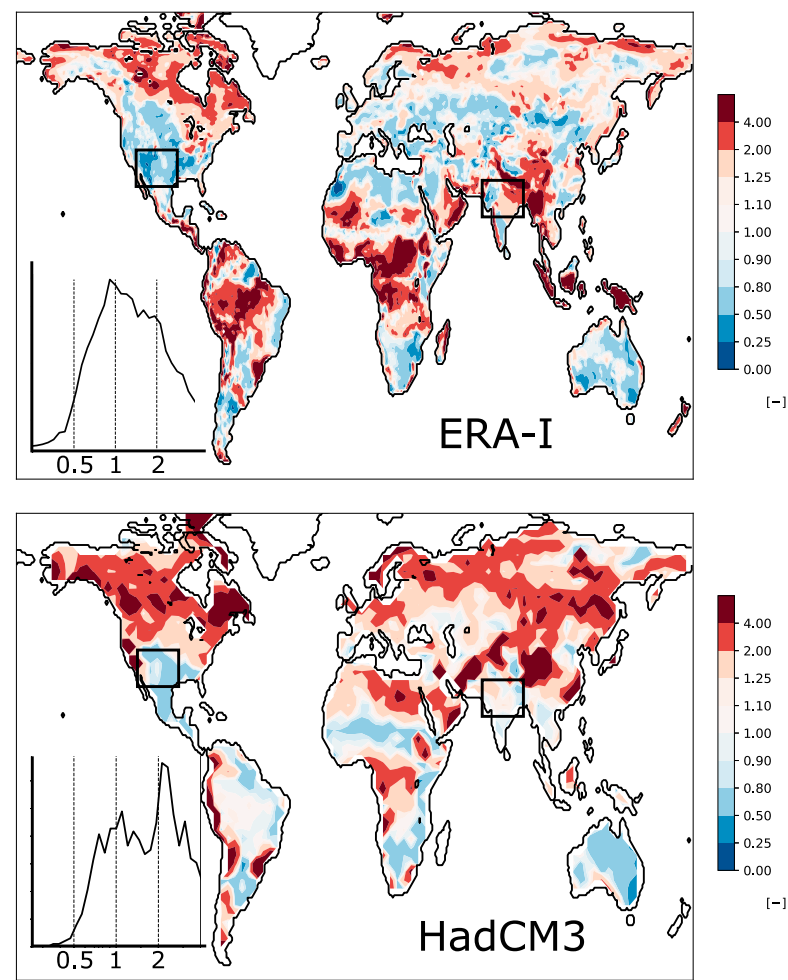

FIG. 10. The variance in summertime 2-m air temperature computed by the toy model with coefficients and forcings from (top) ERA-I and (bottom) HadCM3, normalized by the 2-m air temperature variance in the ERA-I or HadCM3 dataset $\sigma^{2}\left(T_{\mathrm{TM}}\right) /$ $\sigma^{2}\left(T_{\text {data }}\right)$. Insets show histograms of the normalized variance at all mapped points.

soil moisture variability has a small impact on the climate of desert regions and the large overprediction shown in Fig. 11 does not translate to a large absolute error in temperature variance.

In the toy model, soil moisture anomalies preferentially enhance temperature anomalies in dry regions. Hence, a systemic underprediction of soil moisture variance by the toy model (Fig. 11) should result in $\sigma^{2}(T)$ values that are too low in dry regions. Figure 10 clearly shows this behavior: the toy model's systemic underpredictions are found in dry regions like Australia and the southwestern United States.

The impact of soil moisture on summer temperature variance can be estimated by comparing the $\sigma^{2}(T)$ simulated by the toy model in Fig. 10 to the $\sigma^{2}(T)$ simulated with the toy model when $m^{\prime}$ is artificially set to zero in all regions. The normalized difference between these two simulations is shown in Fig. 12. In general, soil moisture anomalies increase temperature variance by $20 \%$ to $80 \%$ in dry regions such as central Asia, Australia, and the western United States [as proposed by Seneviratne et al. (2010); Koster et al. 2015]. This range of values is 

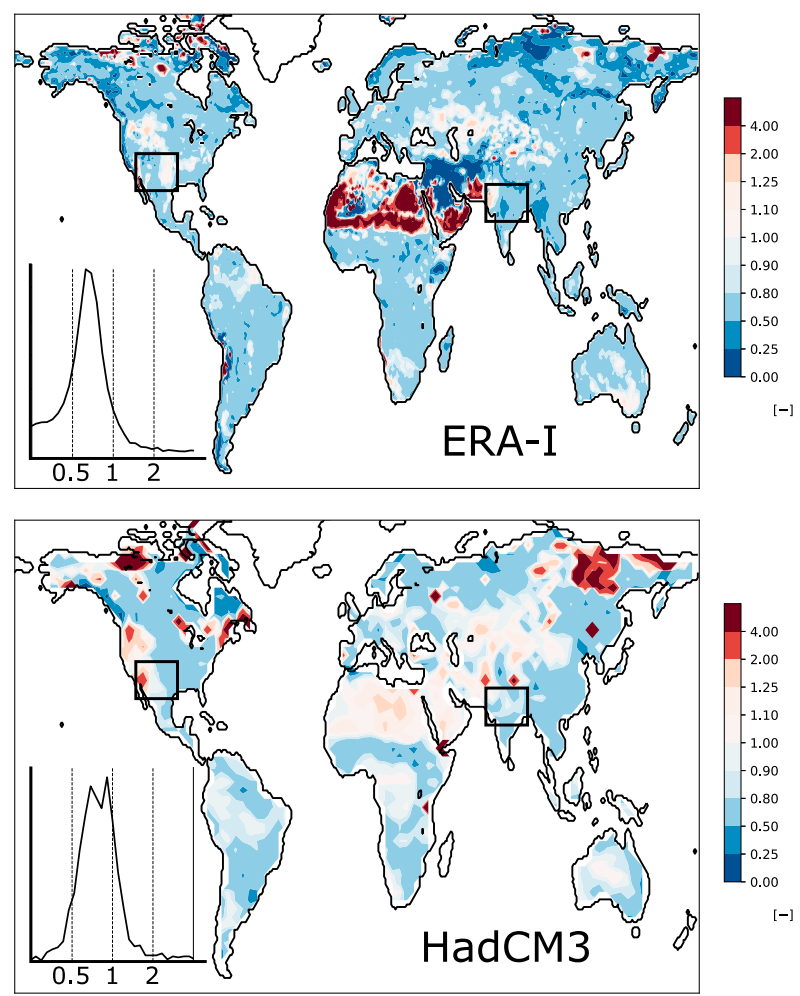

FIG. 11. As in Fig. 10, but for summertime surface soil moisture $\sigma^{2}\left(m_{\mathrm{TM}}\right) / \sigma^{2}\left(m_{\text {data }}\right)$.

broadly consistent with expectations from the toy model; from Eq. (20), including latent heat flux perturbations associated with soil moisture fluctuations increased the temperature variance by $31 \%$ in dry regions $[(4.12-2.84) /$ $4.12=0.31]$.

\section{Understanding climate model biases in $\sigma^{2}(T)$ using the toy model}

In this section, we demonstrate one application of the toy model: understanding biases in summertime temperature variability simulated by climate models. We use the toy model to determine whether the biases in a climate model are predominantly due to errors in soil moisture-latent heat flux coupling or in the radiation and precipitation forcings. We focus on two regions where $\sigma^{2}(T)$ in HadCM3 is more than a factor of 3 greater than that observed: the southwest United States and northern India (see the boxed regions in Fig. 3). These are also regions that both the HadCM3 and ERA-I realizations of the toy model are within a factor of 2 of the temperature variance found in their respective products (see Fig. 10 and Table 4). While all climate models and reanalysis products have different representations of land-atmosphere coupling (Lei et al.2018), we expect that the toy model can shed light on
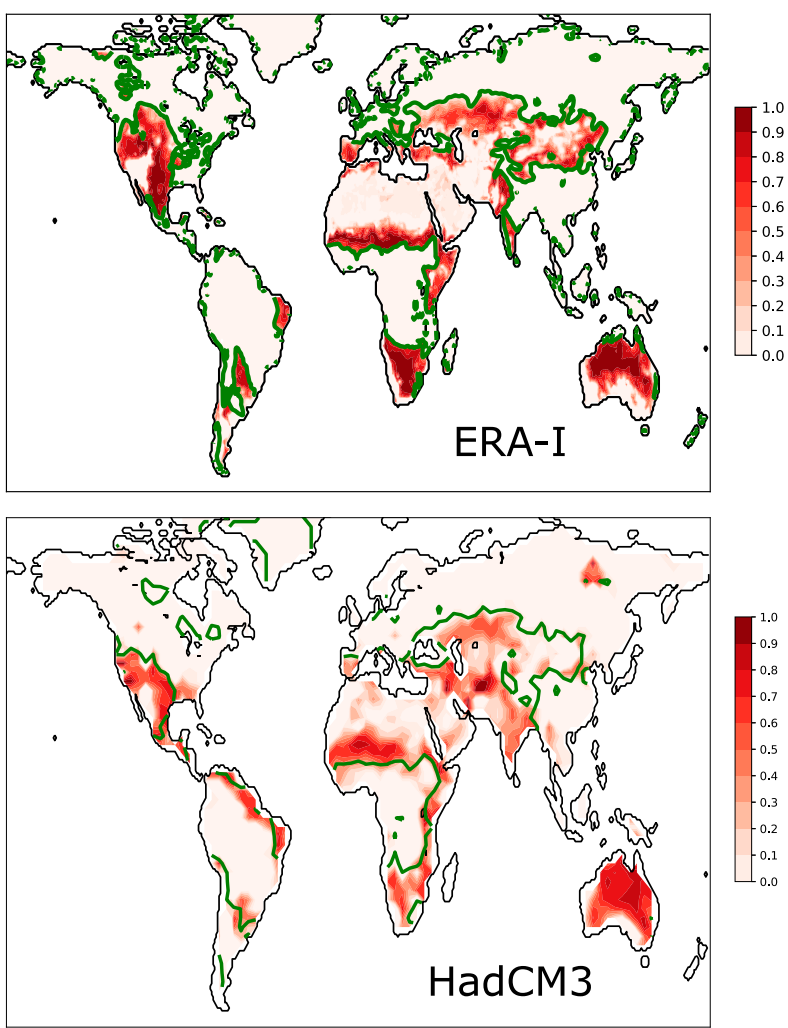

FIG. 12. The impact of soil moisture anomalies on summertime temperature variance in ERA-I and HadCM3. Impact is measured as the normalized change in variance due to the impact of soil moisture anomalies on temperature variance: $\left\{\sigma^{2}\left[T\left(m^{\prime}\right)\right]-\sigma^{2}\left[T\left(m^{\prime}=0\right)\right]\right\} /$ $\sigma^{2}\left[T\left(m^{\prime}\right)\right]$, where $\sigma^{2}(T)$ is given by Eq. (20). The solid green line shows where the summertime climatological soil moisture is equal to the global mean soil moisture.

the processes responsible for biases in individual climate models.

We pose the attribution problem as follows. The toy model expresses the temperature variance as a function of precipitating $(L \alpha \mathscr{P})$ and nonprecipitating $\left(\mathscr{F}_{o}\right)$ radiative forcing, one decomposition coefficient $\alpha$, and six surface parameters [see Eqs. (16) and (20)]:

$$
\begin{aligned}
\sigma^{2}(T) & =\sigma^{2}\left\{\mathscr{\mathscr { F }}_{o}^{\prime}, \mathscr{P}^{\prime}, \alpha ; \gamma, \beta, \lambda, \delta_{H}, \nu_{E}, \nu_{S}\right\} \\
& \equiv \sigma^{2}\{\text { forcing; surface }\}
\end{aligned}
$$

In Eq. (24), the forcing variables $\mathscr{\mathscr { F }}_{o}^{\prime}, \mathscr{P}^{\prime}, \alpha$ and the surface parameters $\gamma, \beta, \lambda, \delta_{H}, \nu_{E}, \nu_{S}$ are separated by a semicolon. We will focus on the forcing terms $\mathscr{\mathscr { H }}_{o}^{\prime}$ and $\mathscr{P}^{\prime}$, and $\nu_{E}$-the parameter governing the connection between soil moisture and latent heat flux. Table 5 shows these values from ERA-I and HadCM3 in the two regions of interest.

In both the southwest United States and over India, the high forcing values in HadCM3 are likely the 
TABLE 4. Quantifying the source of errors in the summer temperature variance over the southwestern United States and northern India simulated in the HadCM3. The first row is the temperature variance from observations (see Fig. 1). The second and third rows are the temperature variances from the same regions in ERA-I and HadCM3 output. The fourth and fifth rows are the results from the toy model with forcing and parameter values from ERA-I and HadCM3, respectively. The last two rows show results from the toy model experiments conducted by substituting the forcing values $\left[\sigma^{2}(\mathscr{F}), \sigma^{2}(\mathscr{P})\right.$, and $\left.\alpha\right]$ and the $\nu_{E}$ parameter in the two realizations of the toy model. Units are $\mathrm{K}^{2}$.

\begin{tabular}{lcc}
\hline \multicolumn{1}{c}{ Experiment } & $\begin{array}{c}\text { South central } \\
\text { United States }\end{array}$ & India \\
\hline Observed (University of Delaware) & 1.37 & 0.70 \\
ERA-I & 1.75 & 0.86 \\
HadCM3 & 3.89 & 3.04 \\
ERA-I forcing; $\nu_{E}$ from ERA-I & 1.13 & 1.31 \\
HadCM3 forcing; $\nu_{E}$ from HadCM3 & 3.73 & 2.89 \\
HadCM3 forcing; $\nu_{E}$ from ERA-I & 3.77 & 2.62 \\
ERA-I forcing; $\nu_{E}$ from HadCM3 & 0.85 & 2.12 \\
\hline
\end{tabular}

primary cause of the high bias in temperature variance. Table 4 shows that replacing the ERA-I forcing with the HadCM3 forcing while retaining ERA-I $\nu_{E}$ values causes the temperature variance to increase by a factor of $3.3(=3.77 / 1.13)$ in the southwest United States and by a factor of $2(=2.62 / 1.31)$ in northern India. Conversely, replacing the HadCM3 forcing with the ERA-I forcing while retaining the HadCM $3 \nu_{E}$ parameter decreases the temperature variance by a factor of $4(=0.85 / 3.73)$ in the southwest United States and by $27 \%(=2.12 / 2.89)$ in northern India.

While biases in the model forcings clearly contribute to HadCM3's high bias in temperature variance over northern India, we can use this attribution procedure to show that this model's representation of land-atmosphere coupling likely contributes to the temperature variance bias in this region. In HadCM3, all of northern India is represented as a dry region (Fig. 12 bottom), and the value of $\nu_{E}$ is correspondingly higher than in ERA-I, where the region is much wetter on average. Replacing the ERA-I $\nu_{E}$ value with the $\nu_{E}$ from HadCM3 while retaining the ERAI forcing amplifies temperature variance by a factor of 1.6 $(=2.12 / 1.31)$ due to the increased influence of soil moisture on temperature fluctuations. Conversely, using the ERA-I
$\nu_{E}$ value in place of the $\nu_{E}$ from HadCM3 while retaining the HadCM 3 forcing reduces the temperature variance by $9 \%(=2.62 / 2.89)$, in line with our findings above, suggesting that temperature variance is muted in climatologically wet regions.

In the southwestern United States, ERA-I has a stronger coupling between soil moisture and latent heat flux than the HadCM3 model; replacing the $\nu_{E}$ from ERA-I with the $\nu_{E}$ from HadCM3 while retaining the ERA-I forcing reduces the temperature variance by $25 \%(=0.85 / 1.13)$. In contrast, replacing the $\nu_{E}$ values from HadCM3 with the $\nu_{E}$ values from ERA-I while retaining the HadCM3 forcing increases the temperature variance only by a factor of 1.01 (3.77/3.73); this insensitivity to changes in $\nu_{E}$ is likely due to the extremely high forcing values over the southwestern United States and other surface parameters from HadCM3.

We have focused on the coupling between soil moisture anomalies and latent heat flux in this analysis, although the plasticity of the toy model allows for the investigation of many processes that contribute to biases in temperature variance. For example, Tétreault-Pinard (2013) used the toy model to identify the sources of temperature variance biases in the central United States and eastern Europe in the historical simulations of the CCSM3.0 and HadCM3 models, used in CMIP3. He found that high biases in both regions of both models were associated with erroneously large soil moisture variability compared to the ERA-40 reanalysis, and not biases in the forcing amplitude.

\section{Discussion and conclusions}

We have developed a linear diagnostic model of the coupled monthly variations in summertime $2-\mathrm{m}$ air temperature and soil moisture that come about because of stochastic variations in forcing-taken to be the monthly anomalies in precipitation $\mathscr{P}^{\prime}$ and net radiative forcing $\widetilde{\mathscr{F}}^{\prime}$. The model is formulated from empirically derived relationships between the forcings, the two state variables (2-m air temperature $T$ and $10-\mathrm{cm}$ soil moisture $m$ ), and the surface fluxes of energy and moisture using ERA-Interim reanalysis and output from a widely used climate model, HadCM3.

TABLE 5. Mean values for summer averaged forcing and $\nu_{E}$ values averaged over the central United States and India from ERA-I and HadCM3 (see boxed regions in Fig. 3).

\begin{tabular}{llrrr}
\hline \multicolumn{1}{c}{ Region } & Product & $\sigma^{2}\left(\mathscr{F}_{o}\right)\left(\mathrm{W}^{2} \mathrm{~m}^{-4}\right)$ & $\sigma^{2}(L \alpha \mathscr{P})\left(\mathrm{W}^{2} \mathrm{~m}^{-4}\right)$ & $\nu_{E}\left(\mathrm{day}^{-1}\right)$ \\
\hline Central United States & ERA-I & 35 & 36 & 0.39 \\
& HadCM3 & 194 & 149 & 0.22 \\
India & ERA-I & 69 & 90 & 0.10 \\
& HadCM3 & 134 & 195 & 0.27 \\
\hline
\end{tabular}




\section{a. Summary of findings}

For the same amplitude of stochastic radiative forcing, the toy model suggests that the temperature variance in dry/moisture-limited regions should be much greater than in wet/energy-limited regions [see discussion following Eq. (20)]. There are two reasons for this: first, a much greater fraction $(\lambda)$ of the radiative forcing is used to evaporate water in wet regions than in dry regions, and so less energy is available to generate temperature anomalies [as argued by Fischer et al. (2012)]. Second, the moisture-related fluctuations in latent heat flux preferentially amplify temperature anomalies in dry regions. The result that soil moisture anomalies enhance the temperature variance in dry regions conforms to the existing literature on land-atmosphere interaction (e.g., Seneviratne et al. 2006, 2010; Hirschi et al. 2011; Koster et al. 2015).

In addition to providing a quantitative framework for understanding the impact of soil moisture anomalies on temperature variance, we demonstrate how the toy model can also be used to illuminate the source of temperature variance bias in a climate model: a regional bias in 2-m air temperature variability could be due to biases in the radiative forcing anomalies, precipitation forcing anomalies, or an erroneous representation of the evaporation-moisture connection or of some other land surface process. We use the toy model to investigate the biases in monthly summertime temperature variance in the southwest United States and in northern India in the HadCM3 model used in CMIP5, finding high biases in temperature variance in both regions because the stochastic forcing was too strong (i.e., due to too much variability in cloudiness). In northern India, HadCM3 simulates stronger soil moisture-latent heat flux coupling compared to the ERA-I output, compounding the high bias in temperature. ${ }^{1}$ Given that most of the CMIP3 and CMIP5 climate models suffer large biases in summertime temperature variance [shown in Fig. 2 and documented in Christensen and Boberg (2012) and Tétreault-Pinard (2013)], it is likely that our model could be used to identify and hopefully remedy the cause of biases in many of the models.

\section{b. Errors and approximations in the toy model}

While the toy model provides a reasonable fit to both ERA-I and HadCM3 temperature variance, it underestimates the variance in soil moisture by about one-

\footnotetext{
${ }^{1}$ Tétreault-Pinard (2013) provides two additional examples of how the toy model can be used to identify the sources of biases in temperature variance.
}

third. We believe the toy model's underestimate is in part due to the exclusion of soil moisture memory and to residuals associated with the parameterization of various terms in the surface energy and water budgets. There is no soil moisture memory in the toy model, but in the real world deep soil moisture dynamics do provide memory that enhances the variance in surface moisture $m$. The one-month autolag in soil moisture in the upper $1 \mathrm{~m}$ of soil is typically $\sim 0.4$ (thicker soil columns have even greater soil moisture memory; Seneviratne and Koster 2012). Adding a memory term does indeed enhance summer moisture variance, but yields equations that obscure physical insight, so we have refrained from doing so.

There are additional structural limitations in the model's present form; we summarize these here:

- We use 2-m air temperature as a state variable, but our model is predicated on an equilibrium land surface energy budget. Recent work (e.g., Gallego-Elvira et al. 2016; Panwar et al. 2019) has suggested that terrestrial turbulent energy fluxes have different signatures on land surface and 2-m air temperature, and our conception of the land-atmosphere interface as a "phantom layer" glosses over potentially important impacts of these turbulent energy fluxes.

- The representation of evapotranspiration in terms of $m^{\prime}$ and $\mathscr{F}^{\prime}$ neglects the complexities of plant canopies, plant root systems, and variations of relative humidity in the lower atmosphere.

- Our two-regime parameterization of evapotranspiration is a reflection of relationships found in both ERA-I and HadCM3 [and in ERA-40 and the two CMIP3 models analyzed by Tétreault-Pinard (2013)]. While this parameterization captures the behavior of these products, Vargas Zeppetello et al. (2019a) found that evapotranspiration is a continuous function of the underlying variables (soil moisture, radiative forcing, etc.) and that the apparent soil moisture regimes in evapotranspiration represent the limits of this function as soil moisture varies.

- Parameterization of the monthly averaged fluxes in terms of simultaneous monthly averaged surface variables may hide important physical relationships, in part because the natural time scales for some processes are much shorter than one month and in part because of our neglect of the system's memory (particularly in soil moisture, which is likely to be the cause of the toy model's systemic low bias in soil moisture variance).

These approximations and simplifications have allowed us insight into the major processes governing summertime temperature variability, and have revealed a basic 
pattern, the "land-muted" versus "land-amplified" dipole in surface moisture impacts on temperature variances. To go further will require a time-dependent model that includes the lower atmosphere and a deeper surface layer, and is written in terms of physical expressions for the relevant processes.

Acknowledgments. The authors thank three anonymous reviewers who offered insightful comments that dramatically improved this manuscript. LRVZ was supported by a NSF Graduate Fellowship, ETP was supported by a grant from the Natural Sciences and Engineering Research Council of Canada, and ETP and DSB were supported by a grant from the Tamaki Foundation. The toy model was originally developed for ETP's master's thesis, and has been updated through this work's progression.

\section{APPENDIX}

\section{Parameterization of the Fluxes in Terms of the State Variables and Forcing}

To write one value $X$ as a linear combination of some other values $Y$ or $Z$ we define a projection operator proj $[X, Y]$ for the $k$ th month of summer $(k=1,2,3)$ :

$$
\begin{aligned}
\operatorname{proj}\left[X^{\prime}, Y^{\prime}\right]_{k} & \equiv \frac{1}{M-1} \frac{1}{\sigma^{2}\left(Y_{k}\right)} \sum_{i=1}^{M} X_{i, k}^{\prime} Y_{i, k}^{\prime} \\
& =\frac{\sigma\left(X_{k}\right)}{\sigma\left(Y_{k}\right)} r_{X Y}(k, k)
\end{aligned}
$$

where $r_{X, Y}$ is the correlation function

$$
r_{X, Y}(k, l) \equiv \frac{1}{M-1} \frac{1}{\sigma\left(X_{k}\right) \sigma\left(Y_{l}\right)} \sum_{i=1}^{M} X_{i, k}^{\prime} Y_{i, l}^{\prime},
$$

$\sigma$ is the standard deviation, $\sigma\left(X_{k}\right) \equiv \sqrt{r_{X, X}(k, k)}$, and $M$ $(=30)$ is the number of samples for each summer.

In the case of ground heat flux, runoff, and upward longwave flux, a single variable explained a large fraction of the flux variance; adding a second projection did not significantly increase the variance explained by the parameterization. In the case of infiltration and sensible heat flux, two variables contributed significantly to the flux variance. In these cases, the parameterization can be done in two ways: 1) first calculate $a=a_{1}=\operatorname{proj}\left[X^{\prime}\right.$, $\left.Y^{\prime}\right]$ and then calculate $b=b_{1}=\operatorname{proj}\left[X^{\prime}-a_{1} Y^{\prime}, Z^{\prime}\right]$, or 2) first calculate $b=b_{2}=\operatorname{proj}\left[X^{\prime}, Z^{\prime}\right]$ and then calculate $a=a_{2}=\operatorname{proj}\left[X^{\prime}-b_{2} Z^{\prime}, Y^{\prime}\right]$, where we have dropped the month subscript for clarity. Since, in general, the variables $Y^{\prime}$ and $Z^{\prime}$ are not independent, $a_{1} \neq a_{2}$ and $b_{1} \neq b_{2}$.
We chose the order for the projections based on the order that minimizes the root-mean-square of the unexplained variance. The first projection is done using the variable that appears in the first term on the RHS of a flux formula. For example, in the parameterization of infiltration Eq. (9),

$$
I^{\prime}=\nu_{\downarrow} m^{\prime}+\beta_{\downarrow} \mathscr{P}^{\prime},
$$

the coefficient $\nu_{\downarrow}=\operatorname{proj}\left[I^{\prime}, m^{\prime}\right]$

and

$$
\beta_{\downarrow}=\operatorname{proj}\left[I^{\prime}-\nu_{\downarrow} m^{\prime}, \mathscr{P}^{\prime}\right] \text {. }
$$

\section{REFERENCES}

Berg, A., and J. Sheffield, 2018: Soil moisture-evapotranspiration coupling in CMIP5 models: Relationship with simulated climate and projections. J. Climate, 31, 4865-4878, https:// doi.org/10.1175/JCLI-D-17-0757.1.

Christensen, J. H., and F. Boberg, 2012: Temperature dependent climate projection deficiencies in CMIP5 models. Geophys. Res. Lett., 39, L24705, https://doi.org/10.1029/2012GL053650.

Dee, D. P., and Coauthors, 2011: The ERA-Interim reanalysis: Configuration and performance of the data assimilation system. Quart. J. Roy. Meteor. Soc., 137, 553-597, https://doi.org/ 10.1002/qj.828.

Dirmeyer, P. A., 2011: The terrestrial segment of soil moistureclimate coupling. Geophys. Res. Lett., 38, L16702, https:// doi.org/10.1029/2011GL048268.

Findell, K. L., P. Gentine, B. Lintner, and C. Kerr, 2011: Probability of afternoon precipitation in eastern United States and Mexico enhanced by high evaporation. Nat. Geosci., 4, 434-439, https://doi.org/10.1038/ngeo1174.

Fischer, E. M., S. Seneviratne, P. Vidale, D. Lüthi, and C. Schär, 2007: Soil moisture-atmosphere interactions during the 2003 European summer heat wave. J. Climate, 20, 5081-5099, https://doi.org/10.1175/JCLI4288.1.

_ J. Rajczak, and C. Schär, 2012: Changes in European summer temperature variability revisited. Geophys. Res. Lett., 39, L19702, https://doi.org/10.1029/2012GL052730.

Gallego-Elvira, B., C. M. Taylor, P. P. Harris, D. Ghent, K. L. Veal, and S. S. Folwell, 2016: Global observational diagnosis of soil moisture control on the land surface energy balance. Geophys. Res. Lett., 43, 2623-2631, https://doi.org/10.1002/ 2016 GL068178.

Guo, Z., and Coauthors, 2006: GLACE: The Global LandAtmosphere Coupling Experiment. Part II: Analysis. J. Hydrometeor., 7, 611-625, https://doi.org/10.1175/JHM511.1.

Hirschi, M., and Coauthors, 2011: Observational evidence for soilmoisture impact on hot extremes in southeastern Europe. Nat. Geosci., 4, 17-21, https://doi.org/10.1038/ngeo1032.

Jaeger, E., and S. Seneviratne, 2011: Impact of soil moistureatmosphere coupling on European climate extremes and trends in a regional climate model. Climate Dyn., 36, 19191939, https://doi.org/10.1007/s00382-010-0780-8.

Koster, R. D., M. J. Suarez, and S. D. Schubert, 2006a: Distinct hydrological signatures in observed historical temperature fields. J. Hydrometeor., 7, 1061-1075, https://doi.org/10.1175/ JHM530.1. , and Coauthors, 2006b: GLACE: The Global Land-Atmosphere Coupling Experiment. Part I: Overview. J. Hydrometeor., 7, 590610, https://doi.org/10.1175/JHM510.1. 
G. Salvucci, A. Rigden, M. Jung, G. Collatz, and S. Schubert, 2015: The pattern across the continental United States of evapotranspiration variability associated with water availability. Front. Earth Sci., 3, 35, https://doi.org/10.3389/ FEART.2015.00035.

Kotlarski, S., and Coauthors, 2014: Regional climate modeling on European scales: A joint standard evaluation of the EUROCORDEX RCM ensemble. Geosci. Model Dev., 7, 1297-1333, https://doi.org/10.5194/gmd-7-1297-2014.

Lei, F., W. T. Crow, T. R. H. Holmes, C. Hain, and M. C. Anderson, 2018: Global investigation of soil moisture and latent heat flux coupling strength. Water Resour. Res., 54, 8196-8215, https:// doi.org/10.1029/2018WR023469.

Lorenz, R., E. Davin, and S. Seneviratne, 2012: Modeling landclimate coupling in Europe: Impact of land surface representation on climate variability and extremes. J. Geophys. Res., 117, D20109, https://doi.org/10.1029/2012JD017755.

— backs on temperature and precipitation extremes in the GLACE-CMIP5 ensemble. J. Geophys. Res. Atmos., 121, 607623, https://doi.org/10.1002/2015JD024053.

Matsuura, K., 2001: The Climate Data Guide: Global (land) precipitation and temperature: Willmott \& Matsuura, University of Delaware. Accessed 11 February 2019, https://climatedataguide.ucar.edu/ climate-data/global-land-precipitation-and-temperature-willmottmatsuura-university-delaware.

McColl, K. A., Q. He, H. Lu, and D. Entekhabi, 2019: Short-term and long-term surface soil moisture memory time scales are spatially anticorrelated at global scales. J. Hydrometeor., 20, 1165-1182, https://doi.org/10.1175/JHM-D-18-0141.1.

Orth, R., and S. I. Seneviratne, 2017: Variability of soil moisture and sea surface temperatures similarly important for warmseason land climate in the Community Earth System Model. J. Climate, 30, 2141-2162, https://doi.org/10.1175/JCLI-D-150567.1.

Panwar, A., A. Kleidon, and M. Renner, 2019: Do surface and air temperatures contain similar imprints of evaporative conditions? Geophys. Res. Lett., 46, 3802-3809, https://doi.org/ 10.1029/2019GL082248.

Previdi, M., 2010: Radiative feedbacks on global precipitation. Environ. Res. Lett., 5, 025211, https://doi.org/10.1088/17489326/5/2/025211.

Ryu, Y., D. Baldocchi, S. Ma, and T. Hehn, 2007: Interannual variability of evapotranspiration and energy exchange over an annual grassland in California. J. Geophys. Res., 113, D09104, https://doi.org/10.1029/2007JD009263.

Schär, C., P. Vidale, D. Lüthi, C. Frei, C. Häberli, M. Liniger, and C. Appenzeller, 2004: The role of increasing temperature variability in European summer heatwaves. Nature, 427, 332 336, https://doi.org/10.1038/nature02300.

Schwingshackl, C., M. Hirschi, and S. I. Seneviratne, 2017: Quantifying spatiotemporal variations of soil moisture control on surface energy balance and near-surface air temperature. J. Climate, 30, 7105-7124, https://doi.org/10.1175/JCLI-D-160727.1.

Seneviratne, S. I., and R. D. Koster, 2012: A revised framework for analyzing soil moisture memory in climate data: Derivation and interpretation. J. Hydrometeor., 13, 404-412, https:// doi.org/10.1175/JHM-D-11-044.1.

_ - D. Lüthi, M. Litschi, and C. Schär, 2006: Land-atmosphere coupling and climate change in Europe. Nature, 443, 205-209, https://doi.org/10.1038/nature05095.

—, T. Corti, E. Davin, M. Hirschi, E. Jaeger, I. Lehner, B. Orlowsky, and A. Teuling, 2010: Investigating soil moistureclimate interactions in a changing climate: A review. Earth-Sci. Rev., 99, 125-161, https://doi.org/10.1016/j.earscirev.2010.02.004.

Tétreault-Pinard, É., 2013: Linking soil moisture and summertime surface temperature variability. Ph.D. thesis, University of Washington, $154 \mathrm{pp}$.

Tett, S. F., and Coauthors, 2007: The impact of natural and anthropogenic forcings on climate and hydrology since 1550 . Climate Dyn., 28, 3-34, https://doi.org/10.1007/s00382-0060165-1.

Teuling, A. J., and Coauthors, 2009: A regional perspective on trends in continental evaporation. Geophys. Res. Lett., 36, L02404, https://doi.org/10.1029/2008GL036584.

Vargas Zeppetello, L. R., D. S. Battisti, and M. B. Baker, 2019a: The origin of soil moisture evaporation "regimes." J. Climate, 32, 6939-6960, https://doi.org/10.1175/JCLI-D-19-0209.1.

— A. Donohoe, and D. S. Battisti, 2019b: Does surface temperature respond to or determine downwelling longwave radiation? Geophys. Res. Lett., 46, 2781-2789, https://doi.org/ 10.1029/2019GL082220.

Vidale, P., D. Lüthi, R. Wegmann, and C. Schär, 2007: European summer climate variability in a heterogeneous multi-model ensemble. Climatic Change, 81, 209-232, https://doi.org/10.1007/ s10584-006-9218-z.

Vogel, M., R. Orth, F. Cheruy, S. Hagemann, R. Lorenz, B. van den Hurk, and S. Seneviratne, 2017: Regional amplification of projected changes in extreme temperature strongly controlled by soil moisture-temperature feedbacks. Geophys. Res. Lett., 44, 1511-1519, https://doi.org/10.1002/2016GL071235.

Weisheimer, A., and T. Palmer, 2005: Changing frequency of occurrence of extreme seasonal temperatures under global warming. Geophys. Res. Lett., 32, L20721, https://doi.org/ 10.1029/2005GL023365. 